\title{
Uncertainty Propagation in Integrated Airframe-Propulsion System Analysis for Hypersonic Vehicles
}

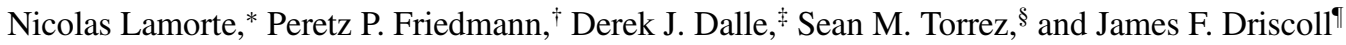 \\ University of Michigan, Ann Arbor, Michigan 48109-2140
}

DOI: $\underline{10.2514 / 1 . B 35122}$

\begin{abstract}
Air-breathing hypersonic vehicles are based on an airframe-integrated scramjet engine. The elongated forebody that serves as the inlet of the engine is subject to harsh aerothermodynamic loading, which causes it to deform. Unpredicted deformations may produce unstart, combustor chocking, or structural failure due to increased loads. An uncertainty quantification framework is used to propagate the effects of aerothermoelastic deformations on the performance of the scramjet engine. A loosely coupled airframe-integrated scramjet engine is considered. The aerothermoelastic deformations calculated for an assumed trajectory and angle of attack are transferred to a scramjet engine analysis. Uncertainty associated with deformation prediction is propagated through the engine performance analysis. The effects of aerodynamic heating and aerothermoelastic deformations at the cowl of the inlet are the most significant. The cowl deformation is the main contributor to the sensitivity of the propulsion system performance to aerothermoelastic effects.
\end{abstract}

$\begin{array}{ll}c & = \\ c_{p} & = \\ E & = \\ \text { ER } & = \\ F_{x} & = \\ f(\xi) & = \\ H & = \\ h & = \\ h_{1}, h_{2} & = \\ h_{3} & = \\ k & = \\ M & = \\ m_{f} & = \\ \dot{m}_{\text {air }} & = \\ \dot{m}_{f} & = \\ P & = \\ q_{\text {aero }} & = \\ q_{\infty} & = \\ R e & = \\ T & = \\ T_{r} & = \\ t & = \\ u & = \\ v & = \\ w & = \\ w_{j} & =\end{array}$

\section{Nomenclature}

specific heat of material

specific heat of air

Young's modulus

equivalence ratio, $\left(\dot{m}_{f} / \dot{m}_{4, \mathrm{O}_{2}}\right) /\left(\dot{m}_{f} / \dot{m}_{4, \mathrm{O}_{2}}\right)_{\mathrm{st}}$

force acting in the $x$ direction

output of interest

altitude

coordinate across thickness of skin

thickness of thermal protection system layers

thickness of structural layer

thermal conductivity

Mach number

expected value of $f$

air mass flow rate

fuel mass flow rate

pressure

aerodynamic heat flux

dynamic pressure

Reynolds number based on length of $1 \mathrm{~m}$

temperature

recovery temperature

flight time

axial displacement

lateral displacement

transverse displacement

weight in numerical integration

$\begin{array}{lll}\left(x^{\prime}, y^{\prime}, z^{\prime}\right) & =\text { coordinate system for corrugated panel } \\ x & =\begin{array}{l}\text { coordinate along vehicle, from leading edge, } \\ \text { positive aft }\end{array} \\ y & =\begin{array}{l}\text { coordinate in spanwise direction, from centerline } \\ \text { of vehicle }\end{array} \\ & =\begin{array}{l}\text { coordinate normal to vehicle, from leading edge } \\ \text { point, positive up }\end{array} \\ z & =\text { angle of attack } \\ \alpha & =\text { thermal expansion coefficient } \\ \alpha_{T} & =\text { angle of attack of trajectory } \\ \alpha_{f} & =\text { uncertain variables } \\ \gamma & =\text { Poisson ratio } \\ \xi_{1}, \xi_{2} & =\text { emissivity } \\ \nu & =\text { density of air } \\ \epsilon & =\text { density of material } \\ \rho & =\text { standard deviation of } f \\ \rho_{M} & =\text { interpolation function } \\ \sigma_{f} & \end{array}$

Subscripts

$i=$ initial value

st $\quad=$ stoichiometric condition

wall $\quad=$ at wall

$0 \quad=$ total condition

$4=$ condition at exit of combustor

$\infty \quad=$ freestream condition
Presented as Paper 2012-5943 at the 18th AIAA/3AF International Space Planes and Hypersonic Systems and Technologies Conference, Tours, France, 24-28 September 2012; received 7 August 2013; revision received 28 April 2014; accepted for publication 6 May 2014; published online 12 August 2014. Copyright (C) 2014 by the authors. Published by the American Institute of Aeronautics and Astronautics, Inc., with permission. Copies of this paper may be made for personal or internal use, on condition that the copier pay the $\$ 10.00$ per-copy fee to the Copyright Clearance Center, Inc., 222 Rosewood Drive, Danvers, MA 01923; include the code 1533-3876/14 and \$10.00 in correspondence with the CCC.

*Graduate Research Assistant, Department of Aerospace Engineering. Student Member AIAA.

${ }^{\dagger}$ François-Xavier Bagnoud Professor, Department of Aerospace Engineering; peretzf@umich.edu. Fellow AIAA.

${ }^{\ddagger}$ Postdoctoral Research Fellow, Department of Aerospace Engineering. Member AIAA.

${ }^{\S}$ Aero Performance Engineer, Department of Aerospace Engineering; currently Brayton Energy, Hampton, NH 03842. Student Member AIAA.

${ }^{\ddagger}$ Modine Professor of Aerospace Engineering, Department of Aerospace Engineering. Fellow AIAA.

\section{Introduction}

$\mathbf{R}$ ESEARCH on hypersonic vehicles is motivated by military and civilian applications such as unmanned rapid response to threats and reusable launch vehicles for affordable access to space [1-7]. For sustained hypersonic cruise speeds, air-breathing engines are needed. Such vehicles are based on lifting body designs with a tightly integrated airframe and propulsion system. A review of the development of ram and scramjet engine propulsion is given in [8]. Airframepropulsion integration, materials, and thermal management as well as computational fluid dynamics (CFD) code analysis and validation methodologies were identified as part of the 10 enabling technologies for sustained hypersonic flight. Only a limited number of airbreathing hypersonic vehicles has flown for a short time period. Among them the X-43 and, more recently, the X-51 are representative vehicles of air-breathing hypersonic aircraft concepts [9], depicted in Fig. 1.

A scramjet engine is a highly integrated propulsion system composed of various components: an inlet, an isolator, a combustor, 


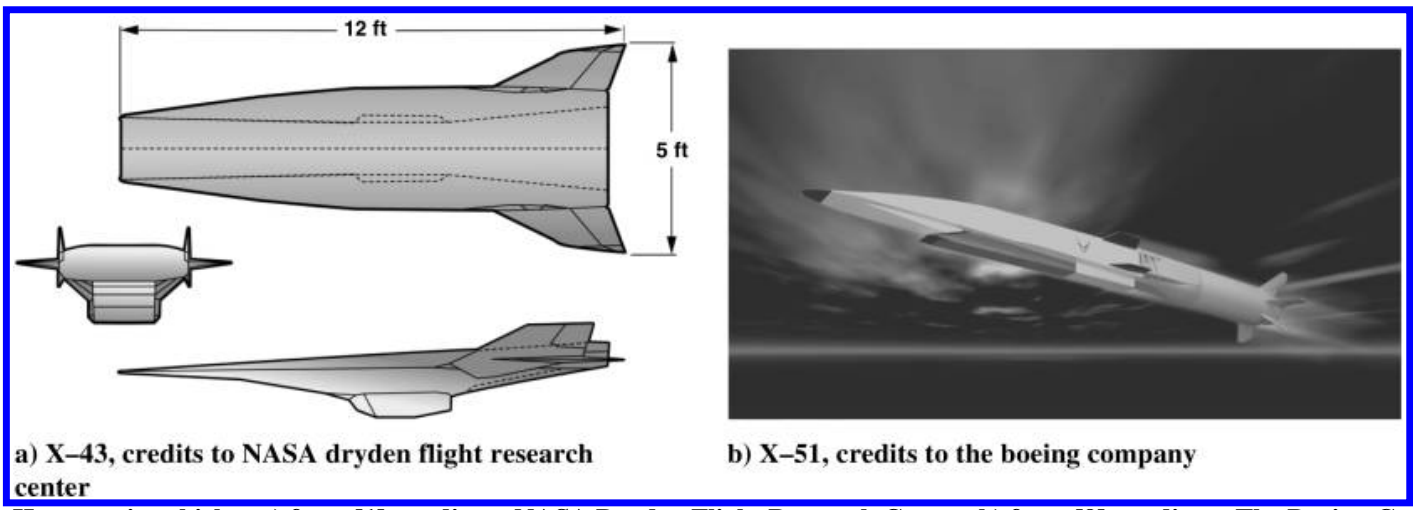

Fig. 1 Hypersonic vehicles: a) from [1] ], credits to NASA Dryden Flight Research Center; b) from [9] , credits to The Boeing Company.

and a nozzle [10]. The structure of the flow in the inlet can be experimentally studied only for short durations for a given flight condition [11,12]. Shocks, expansion fans, boundary layers, detachment and reattachment regions, and their interactions at the inlet are complex and computationally expensive to predict. Aerothermoelastic deformations are neglected; yet several complex issues such as elastic deformation, or creep, and plastic deformation due to high thermal transient loads may occur. Therefore, comprehensive analysis codes must employ models based on simplifying assumptions of the physics and/or reduced-order modeling of fullorder computations. The Michigan Air Force Research Laboratory (AFRL) Scramjet in Vehicle (MASIV) code, developed at University of Michigan, relies on approximate models to provide an efficient tool to investigate design and performance of airframe integrated ramjet-scramjet engine propulsion [13-15] and is used in this study to quantify the effect of thermal deformations on the propulsion system performance. Hypersonic flight within the atmosphere produces severe aerodynamic heating, which can cause vehicle failure. Aerothermoelastic deformations can interact with the propulsion system $[7,16,17]$. Furthermore, hypersonic flight conditions produce high levels of aerodynamic heat flux, shock interactions, viscous interactions, dissociations, and chemically reacting flow $[18,19]$. Accurate modeling of the propulsion system is critical for hypersonic vehicle performance, stability, and reliability analyses. Validation of a fully coupled aerothermoelastic-propulsive system is not feasible due to scaling requirements and a lack of suitable wind tunnels [20]. Therefore, development of hypersonic vehicle simulations requires reliable computational results. Unfortunately, such results cannot be fully validated in ground test facilities [4].

Modeling the aerothermoelastic-propulsion interactions requires several simplifying assumptions in each component of the analysis [7,21]. Simplified models are computationally efficient and enable comprehensive analysis of a hypersonic vehicle in a control-oriented or optimization-oriented framework. To compensate for unmodeled physics and simplifications, an uncertainty propagation approach has been used to quantify sensitivity, robustness, and reliability of a given configuration with respect to identified uncertainties [21-24]. The most effective approaches for propagating uncertainty in aeroelastic problems are direct Monte Carlo simulations (MCSs) [21] and response surface-based methods such as stochastic collocation (SC) or polynomial chaos expansion (PCE). In this study, SC is considered as an effective alternative to direct MCS, which has prohibitive computational costs for complex problems. The SC approach was shown to outperform PCE in a recent study [25] and was successfully used to propagate uncertainty in aeroelastic and aerothermoelastic analyses of hypersonic vehicles [26].

Short-duration and long-duration flights introduce different aerothermoelastic issues. The overall objective of this study is to quantify the effect of variations in geometry due to thermal expansion and stresses and aerodynamic loading in an integrated airframepropulsion system analysis for hypersonic vehicles. This study serves as a guide toward understanding and quantifying uncertainty in studies of an integrated aerothermoelastic-propulsion system of an air-breathing vehicle as well as the overall vehicle behavior or design. The specific goals of this study are as follows:
1) Evaluate aerothermoelastic deformations of the main components of the flowpath of the engine of a typical hypersonic vehicle: the inlet, cowl, and nozzle.

2) Analyze the stability of the propulsion system in a probabilistic manner in order to quantify the risk and reliability associated with uncertainty in the predicted aerothermoelastic deformations.

The following section describes the two-dimensional aerothermoelastic analysis and engine analysis of a generic hypersonic vehicle. The prediction of aerothermoelastic propulsive effects on the engine requires four different analysis capabilities: a propulsion model with deforming geometry capability, a structural model with temperature-dependent material properties, an aerodynamic analysis capable of predicting the heat transfer of external hypersonic flow over a surface, and a heat transfer analysis.

\section{Integrated Airframe-Propulsion System Analysis with MASIV}

The combined aerothermoelastic and engine analyses of a generic hypersonic vehicle is illustrated by the flow chart in Fig. 2 . The prediction of aerothermoelastic propulsive effects on the engine requires four analysis ingredients: a propulsion model with deforming geometry, a structural model with temperature-dependent material properties, an aerodynamic analysis capable of predicting the heat transfer of external hypersonic flow, and a heat transfer analysis.

The vehicle is assumed to be in straight and level flight. The flight condition is determined by the altitude $H$; the Mach number $M_{\infty}$; the angle of attack of the vehicle $\alpha$, which determines the free stream conditions; and the equivalence ratio ER, defined in Sec. II.B. The external aerodynamics and heat transfer equations are solved

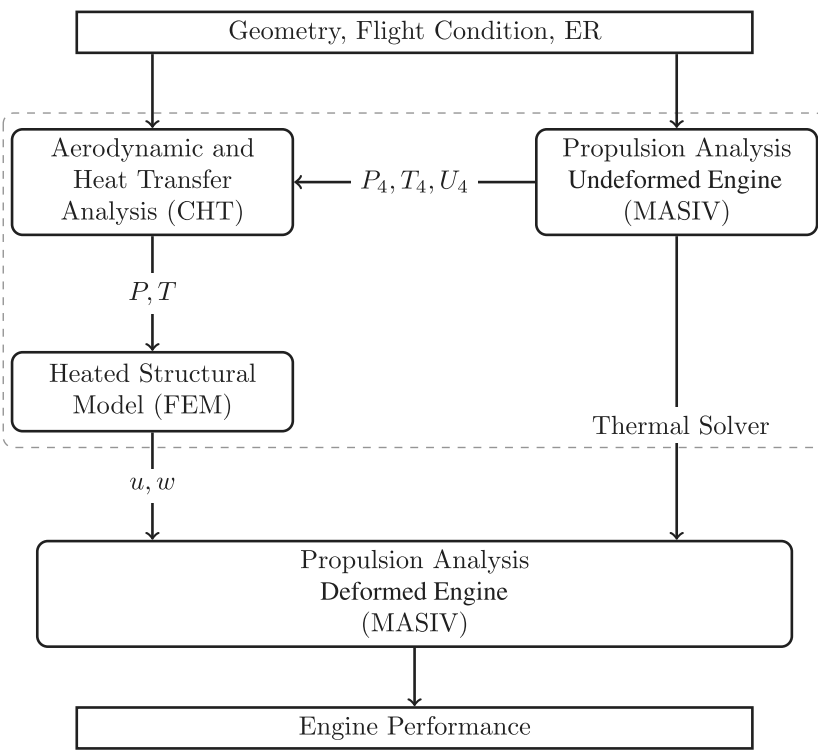

Fig. 2 Modeling flow chart. 
simultaneously. This analysis is referred to as conjugate heat transfer (CHT) analysis. A CHT analysis is performed at given flight, freestream, and combustor conditions to predict the aerodynamic load and temperature distribution in the load-carrying structure as a function of time. Pressure and temperature are transferred to a structural finite-element model (FEM), from which thermal elastic deformation of the vehicle airframe is obtained. The aerothermoelastic analysis is used to estimate the amplitude of maximum static deformations. Because of these assumptions, the deformations are treated as uncertainties. An uncertainty propagation analysis is performed to evaluate the sensitivity of engine performance to the deformed configuration. Each component in the analysis is described in the following subsections.

\section{A. Geometry}

The geometry of the vehicle used in this study is inspired by the X43 depicted in Fig. 3. The $x, y$, and $z$ axes are attached to the body and correspond to the longitudinal, spanwise, and vertical directions, respectively.

This generic geometry is representative of an airframe-integrated air-breathing scramjet propulsion system. The inlet is a slender wedge, which compresses the freestream before it enters the isolator and the combustor. The isolator prevents inlet unstart caused by the increase of pressure in the combustor. Fuel is injected and burns in the combustor. The nozzle ensures expansion of the flow from the combustor conditions to the freestream conditions and generates thrust. The performance of the engine is estimated using a reducedorder model, MASIV, described next.

\section{B. Propulsion System Analysis with MASIV}

The MASIV code is an approximate, control-oriented model of the propulsion system of air-breathing scramjet engines [27,28]. The geometry of the mean flowpath is depicted in Fig. 4. Each section corresponds to a component of the engine. Along the axial direction, the propulsion system is divided into four components: the inlet $(x<13.5)$, the isolator $(13.5<x<14.5)$, the combustor $(14.5<x$ $<15.7)$, and the nozzle $(15.7<x)$. The points indicated in Fig. 4 define the geometry of the mean flowpath.

This study focuses on the performance of the engine. The resultant of the pressure forces in the $x$ direction on the engine flowpath $F_{x}$ is representative of the engine performance with thrust and is the quantity of interest. The number of points defining the compression ramp represents the number of compression shocks, which compress the freestream before it enters the cowl. There are three compression shocks in the inlet ramp, as illustrated in Fig. 4. The steady flow solution is calculated using the shock-expansion approach. Expansion fans are discretized into a finite number of expansion shocks [27]. Marching downstream, shock-shock and shockdiscrete expansion fans interactions are solved by the solution of the local Riemann problem for perfect gas. There are no pressure losses. Given a flight condition (altitude $H$, Mach number $M_{\infty}$, and angle of attack $\alpha$ ), the mean flow properties at the entrance of the engine in the isolator are predicted: density, static pressure, temperature, and velocity. Mean flow properties at the entrance of the engine are computed and fed to the engine model. Enthalpy tables of a calorifically imperfect gas are used to account for high-temperature effect at the entrance of the engine. In a calorically imperfect gas model, the specific heats $c_{p}$ and $c_{v}$ of the fluid vary with temperature due to the excitation of vibrational energy of the molecules of gas [18]. Consequently, $\gamma=\frac{c_{p}}{c_{v}}$ is also a function of temperature. A more accurate prediction of the combustor inflow properties is achieved with this correction. In this model, $\gamma$ in the nozzle has a fixed value that depends on the combustor output. The same model as for the inlet is also used for the nozzle.

The equivalence ratio, ER $=\left(\dot{m}_{f} / \dot{m}_{O_{2}, 4}\right) /\left(\dot{m}_{f} / \dot{m}_{0_{2}, 4}\right)_{\text {st }}$, corresponds to the ratio of the flow mass rate of fuel over the oxygen flow mass rate divided by the same ratio at the stoichiometric condition. An equivalence ratio of 1 corresponds to the stoichiometric mixture of fuel and oxygen. An eqivalence ratio smaller than 1 means that there is more oxidizer than necessary. The equivalence ratio controls the amount of fuel that is injected in the combustor.

The engine model is described in [29]. The combustor model is a one-dimensional (1D) model that solves for the conservation of mass, momentum, and energy using the equation of state and additional algebraic equations marching axially through the combustion duct. An algebraic spreading model allows transverse jet mixing, which is required to model engines which are mixing limited. The steady laminar flamelet model is an approximate combustion model that considers finite-rate chemistry. The chemistry model is expected to be valid for an equivalence ratio between 0.1 and 2. The MASIV code was recently used in a control study of a rigid hypersonic vehicle [14]. The effect of the angle of attack and inflow rate on the forces acting on a full vehicle (the lift, drag, net thrust, and pitching moment) were evaluated and used in a trim analysis.

The mass flow of the fuel is assumed to be independent of the deformation and corresponds to the mass flow at the prescribed equivalence ratio for the undeformed engine. An alternative approach assumes that the amount of fuel depends on the oxidizer mass flow at the entrance of the engine to keep the equivalence ratio constant at all times. In this case, the fuel mass flow is affected by the deformation. The effect of the deformation on engine performance is then amplified. If the capture area decreases due to deformation, the air mass flow rate decreases in the combustor, and the engine generates less thrust. If the equivalence ratio is kept constant when the vehicle

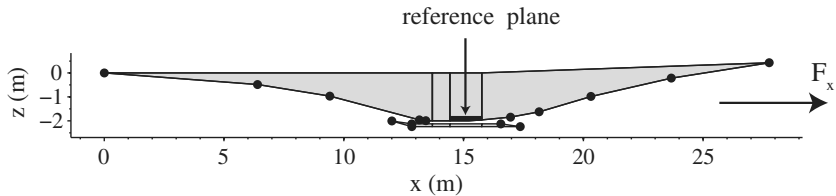

Fig. 4 Engine flowpath.
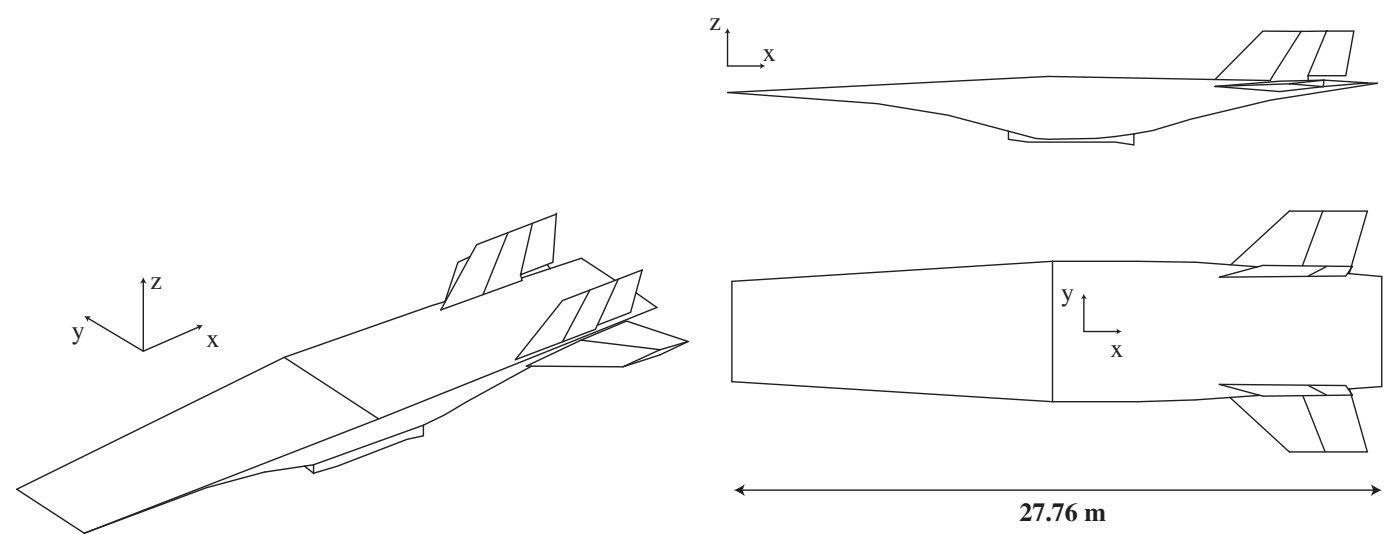

a) Isometric view

b) Side and top views

Fig. 3 Current vehicle geometry. 
deforms, less fuel is injected, and thrust decreases accordingly. The plane corresponding to the top wall of the combustor is the plane of reference for the deformation of the vehicle; see Fig. 4. The points, indicated by circles in Fig. 4, allow the analysis of a deformed engine. These points are used to transfer the deformation from the aerothermostructural model to the engine analysis.

\section{Structural Model}

The structure of an air-breathing hypersonic vehicle is subjected to significant nonuniform aerodynamic heating and pressure loading. Structural components have played a major role in the development and design of hypersonic vehicles [7,30-37]. The structure experiences high-temperature gradients and intense pressure and heat loading, which can cause local buckling or flutter. These challenges require innovative solutions: new high-temperature materials, a thermal protection system (TPS), and possibly coated leading edges with active cooling. The maximum operating temperature of titanium-based alloys varies between 800 and $1300 \mathrm{~K}$ [36,37]. Such materials were studied for potential application in the National Aerospace Plane (NASP) program. In [38], materials for structural components are titanium aluminides and titanium matrix composites. The structural model is developed to estimate the longitudinal aerothermoelastic deformation of the airframe and cowl and identify the principal contributors to aerothermoelastic deflections. The problem of local buckling of the leading edges is ignored. Similarly, issues related with aerothermoelasticity of the wings and control surfaces are not considered.

The MSC.NASTRAN structural model of the vehicle is illustrated in Fig. 5. It contains 540 nodes, 3240 degrees of freedom, and 208 CQUAD 4 shell elements, which represent the skin of the vehicle and the primary load-carrying structure. The interior of the vehicle is filled with 534 CHEXA solid elements to prevent breathing-modestype deformation of the structure. A single element fills in the space between the upper and lower surfaces of the airframe.

There is no reinforcer inside the airframe. The skin is the loadcarrying structure represented by corrugated panels made of a hightemperature titanium alloy in Fig. 6 and described in [39]. The model of the corrugated panel is used to determine the longitudinal Young modulus of the skin of the vehicle. The material properties assigned to the solid elements correspond to an orthotropic material with high stiffness in the $(y, z)$ plane and low stiffness in the $x$ direction. This approach prevents unrealistic breathing modes, and thus the longitudinal deformations of the vehicle depend only on the skin properties. The behavior of the vehicle resembles a sandwich beam where the cross sections remain planar. Material properties are functions of temperature. Thermal stresses are properly accounted for through the thermal expansion coefficient.

The skin of the vehicle is represented by an equivalent panel with homogenized properties [39] given in Table 1. By comparing the specific modulus, i.e., the ratio $\frac{E}{\rho_{M}}$, the corrugated panel is identified as a lighter structure for comparable stiffness requirements. The thickness of top and bottom sheets is $1.5 \mathrm{~mm}$. The corrugated sheet, in Fig. 6, obtained from a superplastical forming and diffusion binding process, is $0.75 \mathrm{~mm}$. The total thickness of the panel $h_{3}$ is $0.03 \mathrm{~m}$. The leading edges are assumed to be perfectly rigid. The upper surface of the internal inlet, isolator, combustor, and internal nozzle are assumed to be made of titanium alloys. The high stiffness associated with this structural component of the airframe where the engine is mounted coincides with the highest thermal and pressure loads.

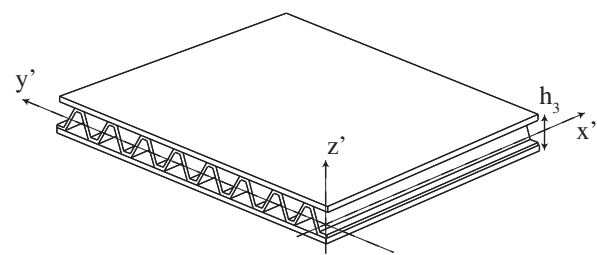

Fig. 6 Truss-core sandwich panel [39].

The total mass of the vehicle, given by the FEM model, is 43 tons. For comparison purposes, the SR-71 is $32.74 \mathrm{~m}$ long, and its empty weight and maximum takeoff weight are 30 and 78 tons, respectively. The rigid-body degrees of freedom are suppressed using the inertia relief option in MSC.NASTRAN. It allows one to compute the free flight deformation of the structure with respect to its reference frame. The computed solution is relative to any rigid-body motion that is occurring. The center of the top wall of the combustor, in Fig. $\underline{4}$, is chosen as the reference point.

The nodal temperature and pressure are computed using a conjugate heat transfer analysis. There is no feedback mechanism to account for the effect of deformation on the aeroheating and heat transfer analysis.

\section{Conjugate Heat Transfer Analysis}

The solution of a structure heated by a fluid flow at one of its boundaries is called the CHT problem. It is used here to estimate the temperature distribution inside the undeformed load-carrying structure of the vehicle as a function of time and flight condition. Temperature distribution in the structure is calculated using CFD++, a commercial finite-volume code capable of solving heat transfer problems in solid and conjugate heat transfer problems [40]. Using $\mathrm{CFD++}$, the Navier-Stokes equations and the heat equation are solved simultaneously for the fluid and structural domains, respectively. Heat flux is conserved through the fluid-TPS and TPSstructure interfaces. The gas model corresponds to calorifically imperfect gas; specific heat $c_{p}$ is function of temperature, and $\gamma$ is not a constant. Turbulence is modeled using the Goldberg turbulence model, which is a single equation model for the undamped eddy viscosity $R_{t}$, recommended for external turbulent hypersonic flows [40].

To protect the load-carrying structure from intense aerodynamic heating, a TPS barrier is placed between the airflow and the structure as depicted in Fig. 7. The TPS is composed of an upper layer of a radiation shield made of PM2000 Honeycomb and a lower internal multiscreen insulation (IMI) barrier, which is a simplified layout used in $[33,41]$. This TPS system is shown to be light and efficient in $[42,43]$. The IMI is also used in [32] as the main heat barrier for a long-range hypersonic vehicle. The thicknesses of the TPS layers are uniform. An optimization analysis is often required in order to design the TPS distribution, such as that performed in [32]. However, it is not performed in the present study.

The mesh for the fluid domain is depicted in Fig. 8. The thin skin structural layout is represented in Fig. 8b. The leading edge of the vehicle experiences high aerodynamic heating. It is a critical component of the vehicle. However, the emphasis of this study is on the body deformation. For this reason, the leading edge is treated as an adiabatic wall in the CHT analysis. This assumption is also used for the cowl boundary. The combustor is the only part of the engine

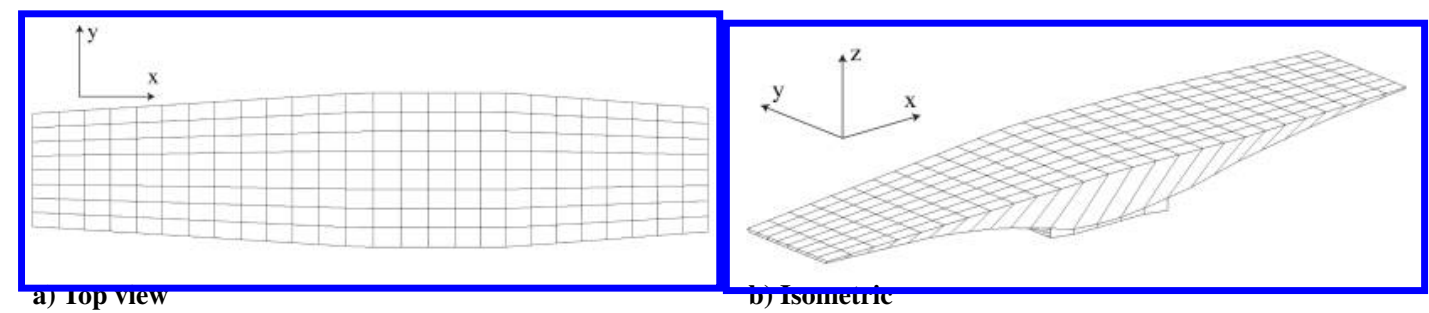

Fig. 5 Structural mesh. 
Table 1 Panel properties

\begin{tabular}{lcc}
\hline \hline Material & Property & Value \\
\hline Titanium alloy & $\rho_{M}$ & $4306 \mathrm{~kg} \cdot \mathrm{m}^{-3}$ \\
& $E$ & $112 \times 10^{9} \mathrm{~Pa}$ \\
& $\alpha_{T}$ & $7.74 \times 10^{-6} \mathrm{~K}^{-1}$ \\
& $\nu$ & 0.3 \\
Titanium alloy panel & $\frac{E}{\rho_{M}}$ & $2.6 \times 10^{7} \mathrm{~m}^{2} / \mathrm{s}^{2}$ \\
& $D_{x}$ & $6.2 \times 10^{4} \mathrm{Nm}$ \\
& $h_{3}$ & $0.03 \mathrm{~m}$ \\
Interior material properties & $\rho_{M}$ & $737.2 \mathrm{~kg} / \mathrm{m}^{3}$ \\
& $\bar{E}=\frac{12 D_{x^{\prime}}\left(1-\nu^{2}\right)}{h^{3}}$ & $32 \times 10^{9} \mathrm{~Pa}$ \\
& $\frac{\rho_{M}}{\rho_{M}}$ & $4.3 \times 10^{7} \mathrm{~m}^{2} / \mathrm{s}^{2}$ \\
& $E_{x}$ & $180 \mathrm{~kg} \cdot \mathrm{m}^{-3}$ \\
& $E_{y}, E_{z}$ & $26 \times 000 \mathrm{~Pa}$ \\
& $\alpha_{T}$ & $7.74 \times 10^{9} \mathrm{~Pa}$ \\
& $\nu$ & 0 \\
\hline \hline
\end{tabular}

that is not represented. The MASIV model is used to estimate the flow conditions at the exit of the combustor. The entrance of the combustor is modeled by an outflow-only boundary condition. There is no backpressure boundary condition in the analysis because the engine is operating in scram mode similarly to the assumption of the MASIV analysis.

Pressure and temperature are linearly interpolated from the entrance of the combustor to the exit of the combustor and then transferred to the structural model. This approximation alleviates the high thermal and pressure loadings that occur in the combustor, a region that has the highest temperature and pressure on the vehicle. Further refinement of both the aerodynamic and structural models is required to capture the aerothermoelastic effects that occur in the combustor. However, modeling these effects is outside the scope of the present study.

Transient temperature distributions in the structure are computed for a level flight trajectory characterized by a constant altitude, Mach

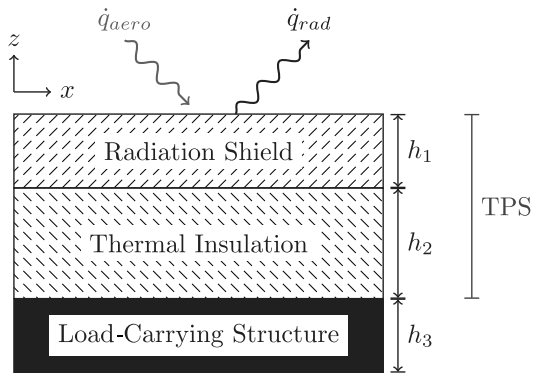

Fig. 7 TPS layout. number, and angle of attack $\alpha_{f}$. Pressure loading is calculated based on the maneuver angle of attack $\alpha$, which maybe different from $\alpha_{f}$, in the case of maneuver, for instance.

\section{E. Uncertain Variables}

The deformation of the engine geometry in MASIV is given by Eq. (1), where $\bar{w}_{1}^{\mathrm{FEM}}$ and $w_{2}^{\mathrm{FEM}}$ refer to the interpolated displacements from the FEM model for the vehicle and the cowl, respectively, at the $(x, z)$ coordinates of the points that define the geometry of the flowpath shown in Fig. 4:

$$
w_{i}^{\mathrm{MASIV}}(x, z)=\xi_{i} \bar{w}_{i}^{\mathrm{FEM}}\left(x, z ; t, \alpha_{f}\right), \quad i=1,2
$$

The deformed shapes of the body of the vehicle $\bar{w}_{1}^{\mathrm{FEM}}$ and the cowl $\bar{w}_{2}^{\text {FEM }}$ determined by a flight history characterized by $\alpha_{f}$ and a flight time $t$ are treated as the maximum possible deformations of the vehicle. The amplitudes of the deformations of the vehicle and the cowl, $\xi_{1}$ and $\xi_{2}$, respectively, are treated as variables in an uncertainty propagation analysis for engine performance. The axial displacement $u$ is treated the same way. Ideally, the probability density functions (PDFs) of the uncertain variables would be quantified using data of flights for a range of vehicles and trajectories. In this study, this information is not available, and the variables are arbitrarily assumed to be uniformly distributed.

\section{Uncertainty Propagation Analysis}

Once the sources of uncertainty have been identified and quantified by appropriate probability distributions, the effect of uncertainty can be studied using two methods: intrusive and nonintrusive approaches [44-46]. The hypersonic propulsion problems require the use of nonintrusive methods due to their complexity. Based on a previous study on uncertainty propagation in aeroelastic and aerothermoelastic analyses [26], stochastic collocation has been identified as an effective alternative to direct Monte Carlo simulation and was selected for this study.

Direct MCS requires numerous evaluations of the function of interest (e.g., $F_{x}$ ), at different values of the uncertain inputs, determined from their probability distribution. It has been a widely used approach in relatively simple studies and is guaranteed to converge to the correct probability distribution for the output when the number of analysis runs is increased. Direct MCS can be applied to any output of interest, even when discontinuities are present. In MCS, depending on the number of input variables and the degree of nonlinearity between $\xi$ and $f(\xi)$, the computational cost associated with the numerous analysis evaluations for complex problems can be prohibitive. Response surface methods are an efficient alternative for reducing the computational cost of the uncertainty propagation analyses.

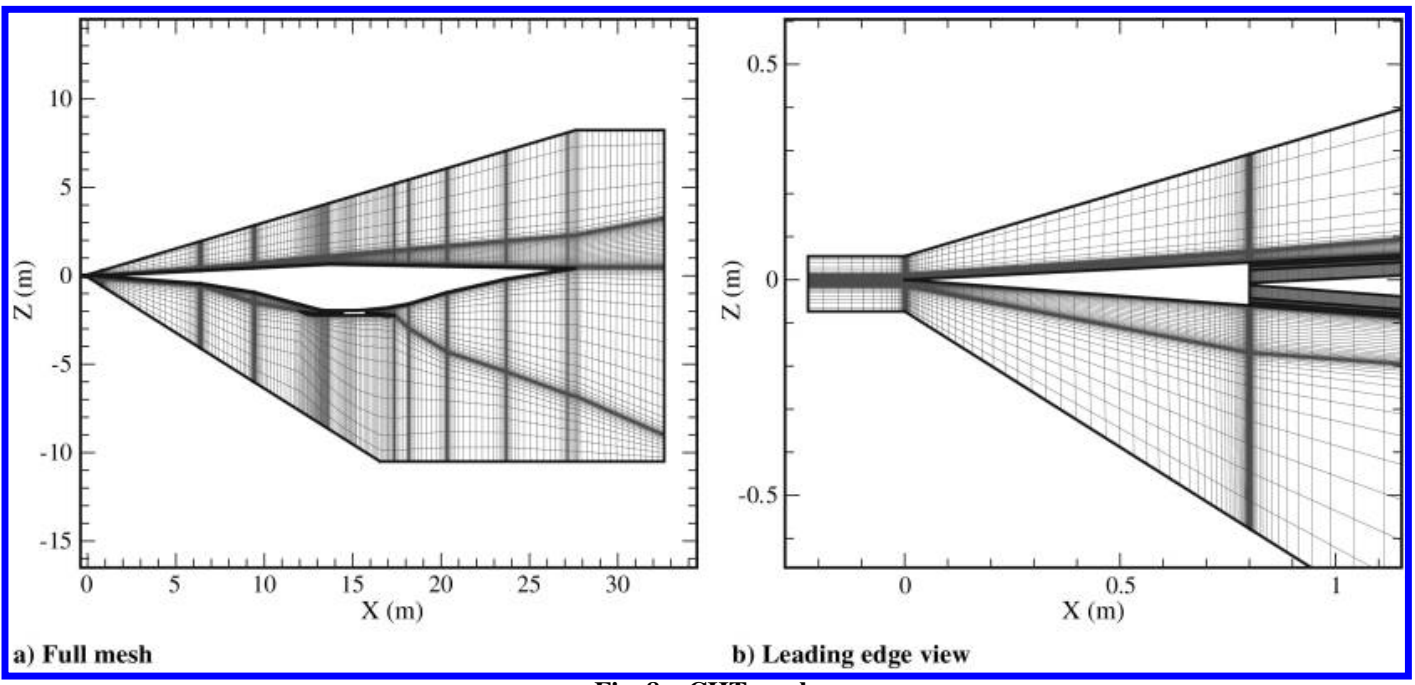

Fig. 8 CHT mesh. 
In SC, computationally efficient polynomial response surfaces are used to approximate the functional relationship between uncertain inputs $\xi$ and the output of interest $f(\xi)$, where $\xi$ is a normalized random variable between the limits -1 and 1 :

$$
f(\xi) \approx \hat{f}(\xi)=\sum_{j=1}^{P+1} A_{j} \phi_{j}(\xi)
$$

The response surface $\hat{f}$ given by Eq. (2) consists of an expansion in terms of polynomial basis functions $\left(\bar{\phi}_{j}(\xi)\right)_{1<j<P+1}$, in which $A_{j}$ are fitting coefficients and $P+1$ represents the number of basis functions. Once constructed, MCS can be applied to the computationally inexpensive polynomial response surface in order to obtain the probability distribution associated with the output of interest.

In the current study, the expensive analyses are evaluated at a set of inputs $\xi$, called collocation points. The collocation points are chosen such that mean $m_{f}$, given by Eq. (3), and variance $\sigma_{f}^{2}$, given by Eq. (4), are estimated using a numerical integration scheme defined by $N_{I}$ integration points $\left(\xi_{k}\right)_{k=1, N_{I}}$ and their corresponding weights $\left(w_{k}\right)_{k=1, N_{I}}$. Thus, the collocation points correspond to the numerical integration points:

$$
\begin{gathered}
m_{f}=\int_{\Omega} p(\xi) f(\xi) \mathrm{d} \xi \simeq \sum_{k=1}^{N_{I}} w_{k} f\left(\xi_{k}\right) \\
\sigma_{f}^{2}=\int_{\Omega} p(\xi)(f(\xi)-\langle f\rangle)^{2} \mathrm{~d} \xi \simeq \sum_{k=1}^{N_{I}} w_{k}\left(f\left(\xi_{k}\right)-\langle f\rangle\right)^{2}
\end{gathered}
$$

The numerical integration scheme is computed using Gaussian quadrature [47]. For a single random variable, the numerical integrations points are the roots of the Legendre polynomial function of degree $N_{I}$ associated with the uniform probability distribution of the input. The numerical integration scheme is exact for polynomial functions of order less than $2 N_{I}-1$.

For the 1D case, the polynomial response surface, given by Eq. (2), is generated using Lagrange polynomials $\left(\phi_{j}\right)_{j=1, P+1}$, Eq. (ㅁ) associated with the collocations points $\left(\xi_{k}\right)_{k=1, N_{I}}$, and Eq. ( $\left.\underline{6}\right)$ :

$$
\begin{gathered}
\phi_{j}(\xi)=\prod_{k=1, k \neq j}^{N_{I}} \frac{\xi-\xi_{k}}{\xi_{j}-\xi_{k}}, \quad j=1, P+1 \\
\phi_{j}\left(\xi_{k}\right)=\delta_{j k}, \quad k=1, N_{I}, \quad j=1, P+1
\end{gathered}
$$

The degree of the polynomial approximation $P$ in Eqs. (ㅁ) and (무) is equal to $N_{I}-1$. For a multidimensional random input space, $\boldsymbol{\xi}=\left(\xi^{i_{v}}\right)_{i_{v}=1, N_{v}}$, in which $N_{v}$ is the number of uncertain inputs, the multivariate extension of Eq. ()ㅡㄹ is given by Eq. (7):

$$
\phi_{j}(\boldsymbol{\xi})=\prod_{i_{v}=1}^{N_{v}} \prod_{k=1, k \neq j}^{N_{I}} \frac{\xi^{i_{v}}-\xi_{k}^{i_{v}}}{\xi_{j}^{i_{v}}-\xi_{k}^{i_{v}}}, \quad j=1, P+1
$$

Since there is strong evidence that the SC approach has outperformed polynomial chaos expansion [25], another widely used technique, SC is the method selected for the current study. Note that this method suffers from the curse of dimensionality, which implies that increasing the number of random inputs exponentially increases the number of analysis runs and the computational cost of the method. The number of analyses required for the implementation of the SC approach is $(P+1)^{N_{v}}$ due to the tensor-product interpolation required by Eq. (7). Furthermore, the collocation points associated with most integration schemes are located strictly within the domain of the input variable. Therefore, extrapolation is required for response surface evaluations close to the domain boundaries, which may adversely affect accuracy.

To prevent extrapolation, the bounds of the interval are added to the set of the integration points with weight $w_{k}=0$, as illustrated in Fig. 9a. These additional collocation points do not improve the accuracy of the integration scheme but ensure that the boundary of the uncertain parameter space is discretized and that there is no extrapolation. It will be referred to as extended stochastic collocation (ESC). Other efficient interpolation techniques can be employed to create the response surface such as adaptive sparse grid interpolation $[\underline{48,49]}$, Kriging surrogates [50], or multivariable splines [51,52] if discontinuities are present.

Once constructed, MCS can be applied on the computationally inexpensive polynomial response surfaces to obtain the probability distributions associated with the output of interest, and this process is referred to as indirect Monte Carlo simulation (IMCS). Latin hypercube sampling (LHS) is used to perform the statistical analysis. LHS is usually employed for space filling sampling, which is the equivalent of a uniform PDF. In Fig. 9b, each cell of the grid has the same probability equal to $1 / 100$. L HS explores the uncertain variables space more efficiently than a Cartesian grid, represented by plus symbols and labeled uniform in Fig. 9b, and sampling points do not cluster as much as for the random number generator, represented by crosses and labeled random.

The efficient uncertainty analysis accounts for approximations in the calculation of the displacement. Transferring the deformation as random variables is effective for mitigating the effect of approximations and facilitates the introduction of deformation at an early stage in the design.

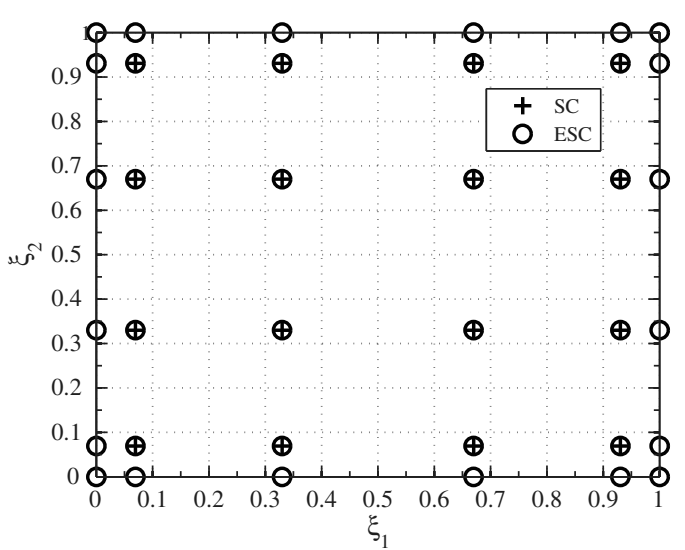

a) Collocation points

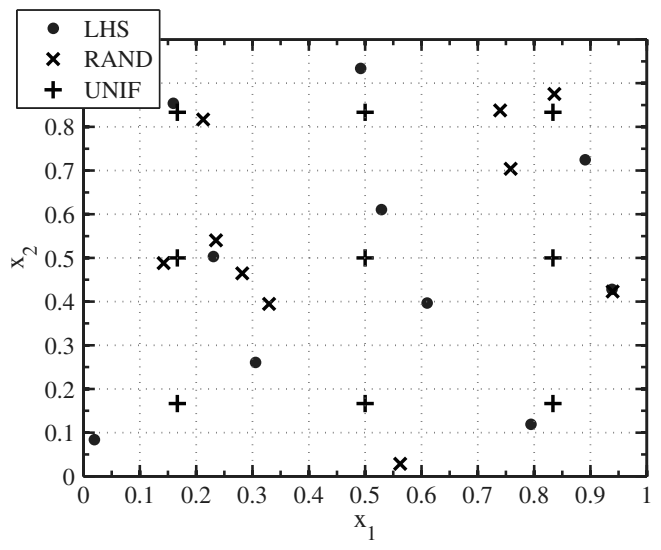

b) Sampling points

Fig. 9 Illustration of different sampling approaches for two uniformly distributed random variables $\xi_{1}$ and $\xi_{2}$ in $[0,1]^{2}$. 
Table 2 Freestream conditions

\begin{tabular}{lcc}
\hline \hline \multicolumn{1}{c}{ Parameter } & & Value \\
\hline Angle of attack & $\alpha$ & $0 \mathrm{rad}$ \\
Altitude & $H$ & $26 \mathrm{~km}$ \\
Mach number & $M_{\infty}$ & 8 \\
Static pressure & $p_{\infty}$ & $2183.8 \mathrm{~Pa}$ \\
Temperature & $T_{\infty}$ & $222.56 \mathrm{~K}$ \\
Stagnation temperature & $T_{0, \infty}$ & $3071.3 \mathrm{~K}$ \\
Density & $\rho_{\infty}$ & $0.0342 \mathrm{~kg} \cdot \mathrm{m}^{-3}$ \\
Reynolds number & $R e_{, \infty}$ & $5.62 \times 10^{6} \mathrm{~m}^{-1}$ \\
Dynamic pressure & $q_{\infty}$ & $96,000 \mathrm{~Pa}(2000 \mathrm{psf})$ \\
\hline \hline
\end{tabular}

Table 3 Combustor conditions

\begin{tabular}{lcc}
\hline \hline \multicolumn{1}{c}{ Parameter } & & Value \\
\hline Mach number & $M_{4}$ & 1.95 \\
Static pressure & $p_{4}$ & $3.5742 \cdot 10^{5} \mathrm{~Pa}$ \\
Temperature & $T_{4}$ & $2039.0 \mathrm{~K}$ \\
Stagnation temperature & $T_{0,4}$ & $3584.7 \mathrm{~K}$ \\
Density & $\rho_{4}$ & $0.47 \mathrm{~kg} \cdot \mathrm{m}^{-3}$ \\
\hline \hline
\end{tabular}

Table 4 TPS material properties

\begin{tabular}{lcccc}
\hline \hline & $\begin{array}{c}\text { Symbol and } \\
\text { unit }\end{array}$ & PM 2000 & IMI & Structure \\
Parameter & $h_{i}, \mathrm{~m}$ & 0.0074 & .01 & 0.03 \\
Thickness & $\rho_{M}, \mathrm{~kg} / \mathrm{m}^{-3}$ & 7196.567 & 72.864 & 4306 \\
Density & $\epsilon$ & 0.75 & -- & $--\overline{-}$ \\
Emissivity & $k, \mathrm{~W} / \mathrm{m} / \mathrm{K}$ & 18.25 & 0.0582 & 21.9 \\
Thermal & & & & \\
conductivity & $c, \mathrm{~J} / \mathrm{kg} / \mathrm{K}$ & 770 & 107 & 540 \\
Specific heat &
\end{tabular}

\section{Results}

The vehicle is assumed to be $27.8 \mathrm{~m}$ long, and this length has been chosen based on the work done on NASP and Hyper-X programs as well as previous concepts [7,16,34,53]. In [28], the performance of two different flowpath geometries of the system inlet-combustor nozzle are compared. The first configuration is optimized for a single flight condition being $M_{\infty}=8, H=26014.5 \mathrm{~m}$ and $\alpha=0 \mathrm{deg}$. The second configuration is designed to be less sensitive to changes in the freestream Mach number and angle of attack [28]. Both geometries yield three compression shocks in the inlet ramp and two compression turns in the cowl. The more robust geometry contains an additional turn at the shoulder of the inlet, which defines the entrance of the internal inlet. This geometry is what is used in this study, as described in Fig. 4.

The flight condition used in this study corresponds to Mach 8 at an altitude of $26 \mathrm{~km}(85,000 \mathrm{ft})$ with 0 deg angle of attack, which corresponds to the average design conditions of the inlet [27]. The freestream condition is given in Table 2. Using the MASIV code, the average flow conditions at the exit of the combustor, given in Table 3 , are obtained. These conditions at the exit of the combustor are used in the CHT analysis as boundary conditions.

\section{A. Conjugate Heat Transfer}

The thermal properties and thicknesses of the TPS layers are given in Table 4.

The $\overline{C H}$ T results are depicted in Figs. $10 \mathrm{a}, 10 \mathrm{~b}, 10 \mathrm{c}$, and $10 \mathrm{~d}$, which show temperature, pressure, Mach, and $\gamma$ contours around the vehicle, respectively. On the upper surface, the flow experiences a compressive shock at the leading edge followed by an expansion after the second edge downstream as observed in Figs. 10a, 10b, and 10c. On the lower surface, the freestream experiences three compression shocks before it reaches the leading edge of the cowl and enters the internal inlet and isolator where a series of shocks occurs. At the nozzle, the flow expands, creating propulsive force for the vehicle. In the internal inlet and expansion fan as well as boundary layers, the static temperature of the fluid is much higher, and $\gamma$ is reduced to 1.3 as indicated in Fig. 10d. The reduction of $\gamma$ illustrates the importance of high-temperature modeling for these regions.

The temperature at the lower surface of the skin as function of time is shown in Fig. 11. During flight, the load-carrying structure heats up through the TPS. The aerodynamic heating rate is higher at the lower surface of the vehicle. Consequently, the temperature rise is significant at the lower surface. Note that most of the vehicle remains at a temperature lower than $800 \mathrm{~K}$ for the first hour of flight.
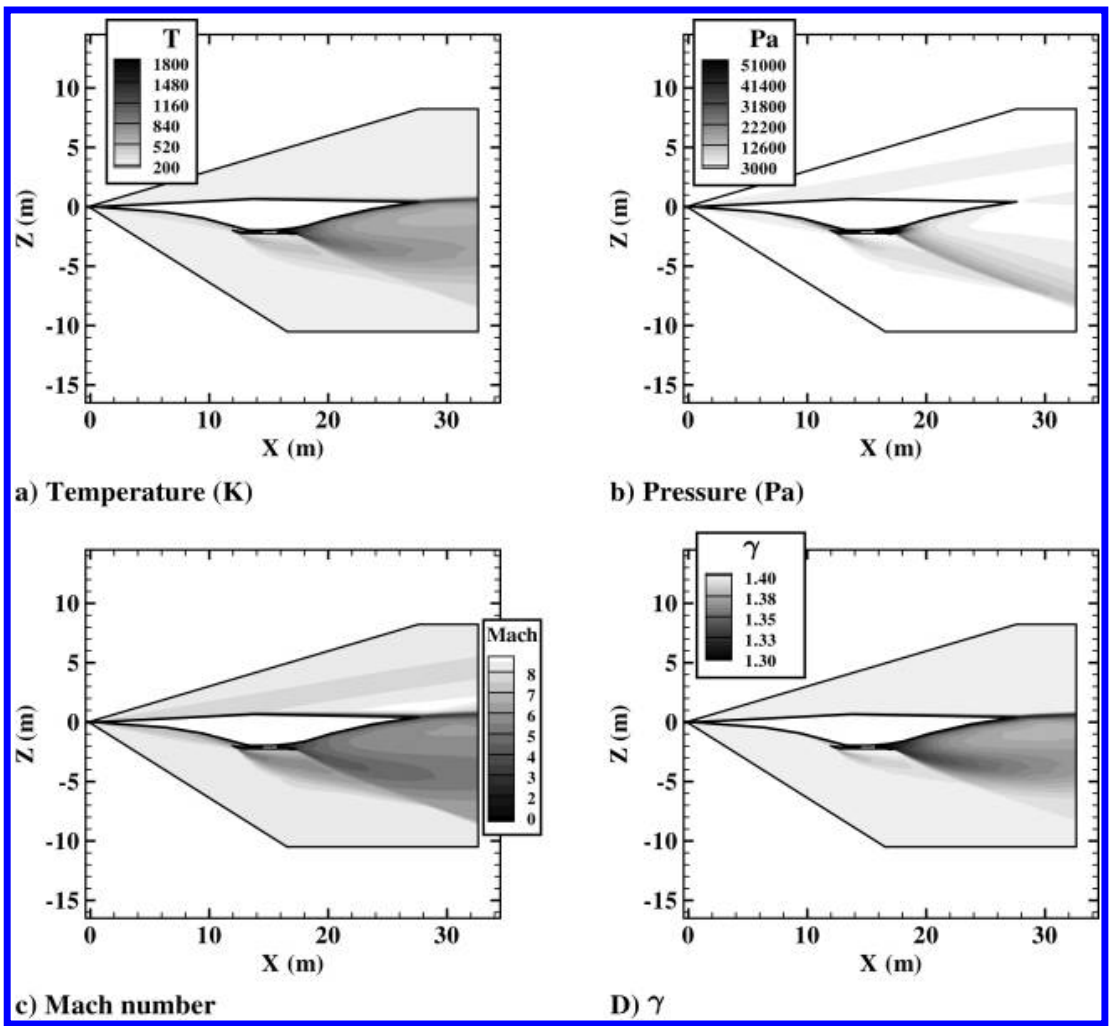

b) Pressure (Pa)

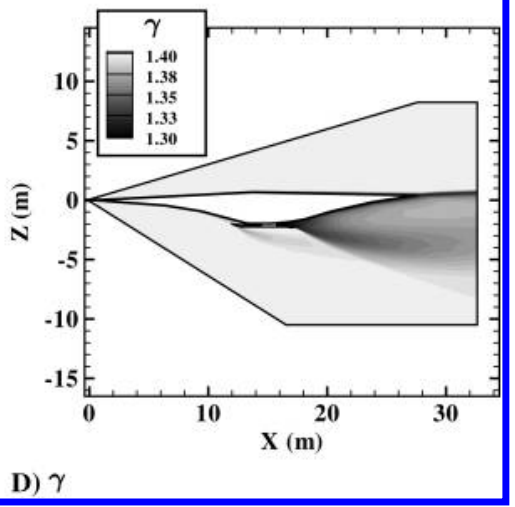

Fig. 10 CHT results. 


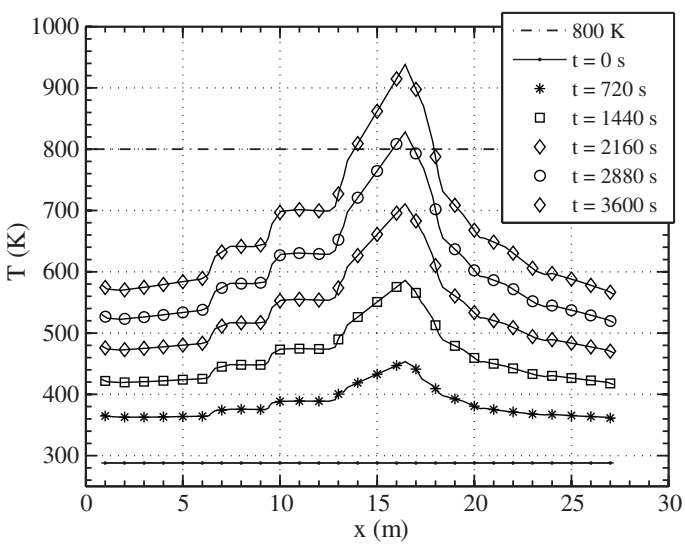

a) Upper skin

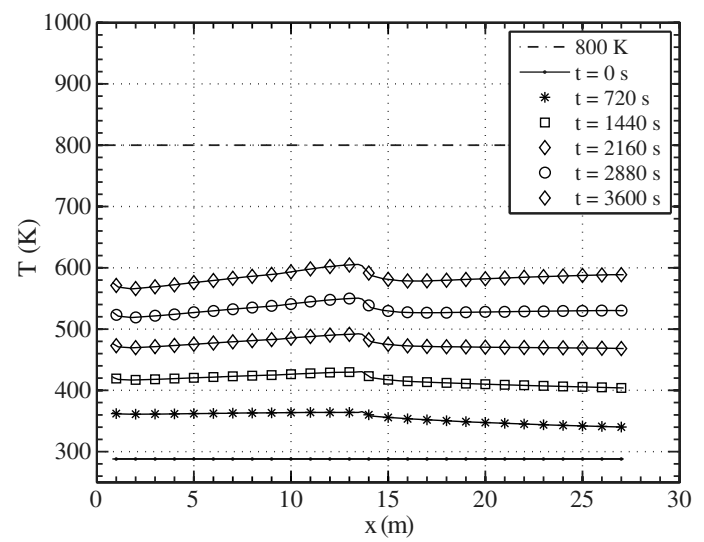

b) Lower skin

Fig. 11 Temperature in the skin as a function of time; $\alpha_{f}=0 \mathrm{deg}$ and $\mathrm{ER}=1.0$.

The central part of the engine (internal inlet, isolator, and internal nozzle) experiences the highest temperatures and may require an additional thermal protection system or active cooling. The exact structural layout or cooling technology for those components is currently not well defined.

The temperature distribution across the thickness of the vehicle, depicted in Fig. 12, corresponds to four different locations of the vehicle surface. These stations correspond to the location of the first compression turn in the inlet ramp, Fig. 12a, and the last compression turn in the nozzle, Fig. 12b, at the upper surface. Their equivalents on the lower surface of the vehicle are given in Figs. 12c and 12d, respectively. The temperature in the thin structure is considered uniform across the thickness compared to the variation in the longitudinal direction. Consequently, temperature gradients across the thickness have a negligible effect on the deformations. Thermal strains develop due to the different temperatures of the upper and lower surfaces of the vehicle.

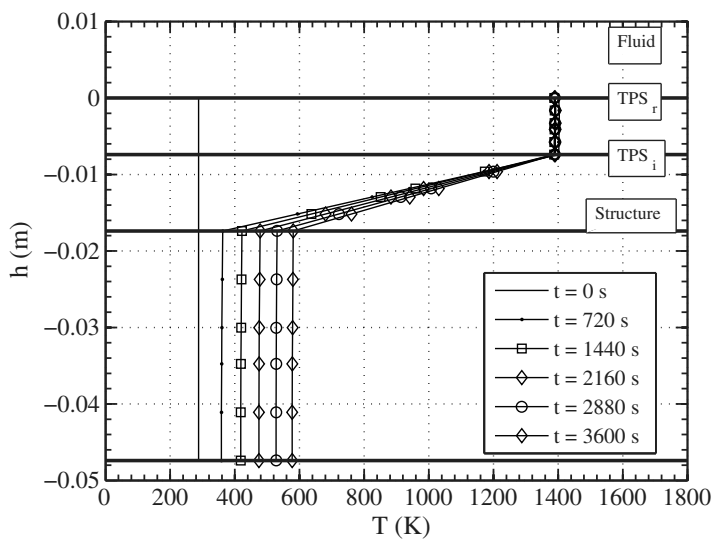

a) Upper skin, $x=6.4 m$

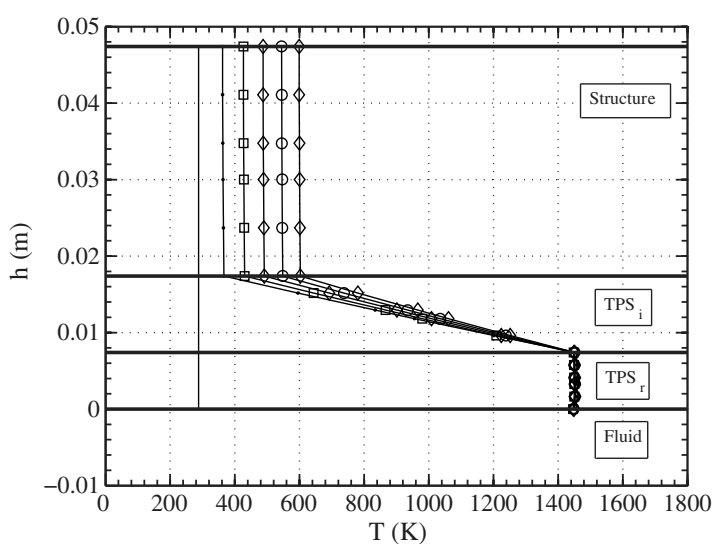

c) Lower skin, $x=6.4 m$
A two-dimensional (2D) CHT model is used to compute the 2D loads on the three-dimensional FEM model. Temperature is linearly interpolated from the CHT results to the structural model as illustrated in Fig. 13a, where the symbols and lines represent information pertaining to the FEM model and the CHT model, respectively, for both upper and lower surfaces of the vehicle body. The nodal pressures applied at each node are calculated based on their longitudinal coordinate $x$ such that the total pressure applied along the centerline of the vehicle is conserved. In Fig. 13b, the nodal pressure is represented by square symbols. To conserve pressure loading, the pressure at the nodes may be different than the linearly interpolated value. As a first approximation, the pressure on the lateral sides of the vehicle is interpolated from the upper surface to the lower surface. The leading edges and trailing edges of the vehicle are assumed to be rigid and are not represented in the FEM model. However, the resultant aerodynamic forces and moments on the

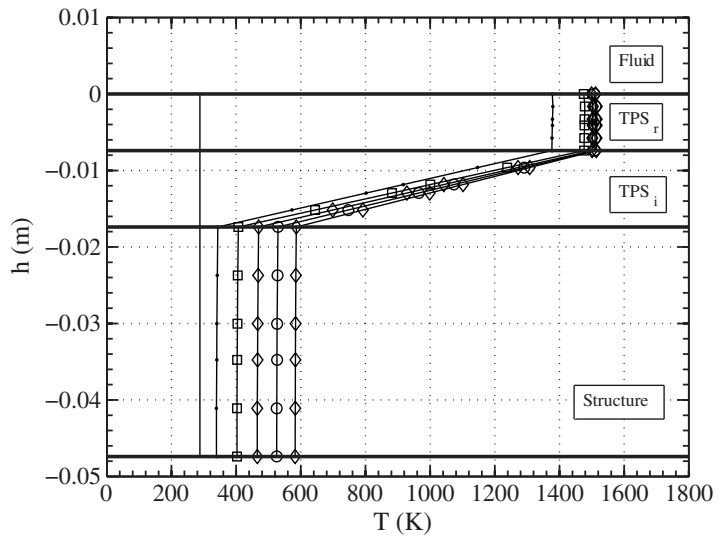

b) Upper skin, $x=23.7 \mathrm{~m}$

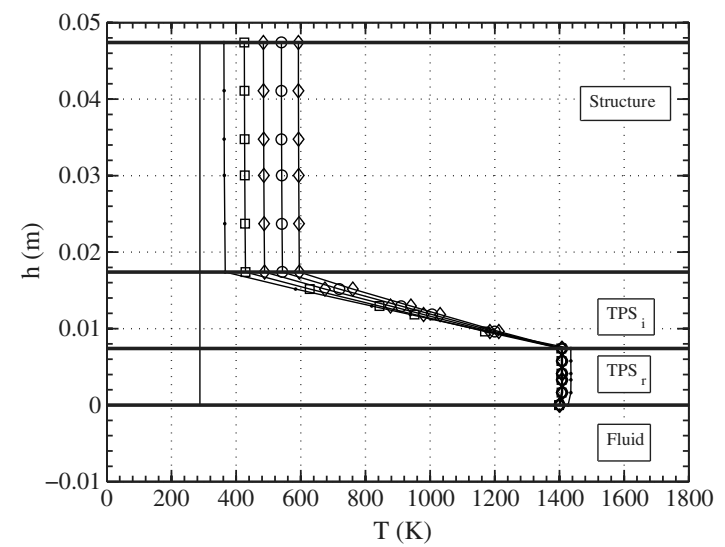

d) Lower skin, $x=23.7 \mathrm{~m}$

Fig. 12 Temperature across skin thickness; $h=0$ corresponds to the TPS-freestream interface. 


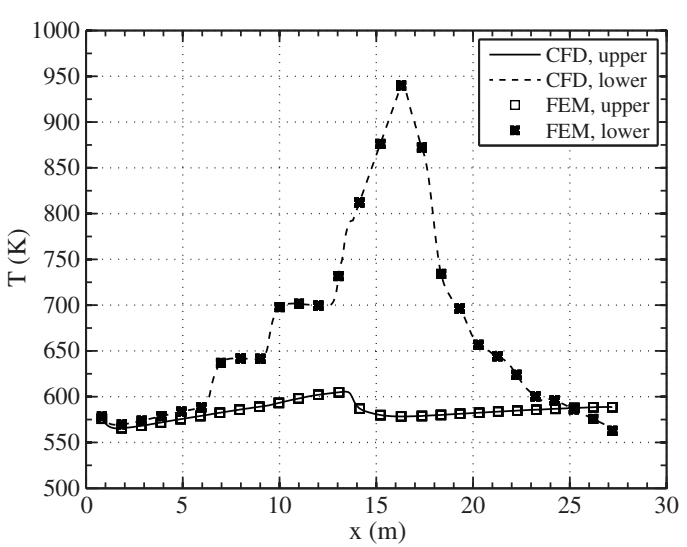

a) Temperature

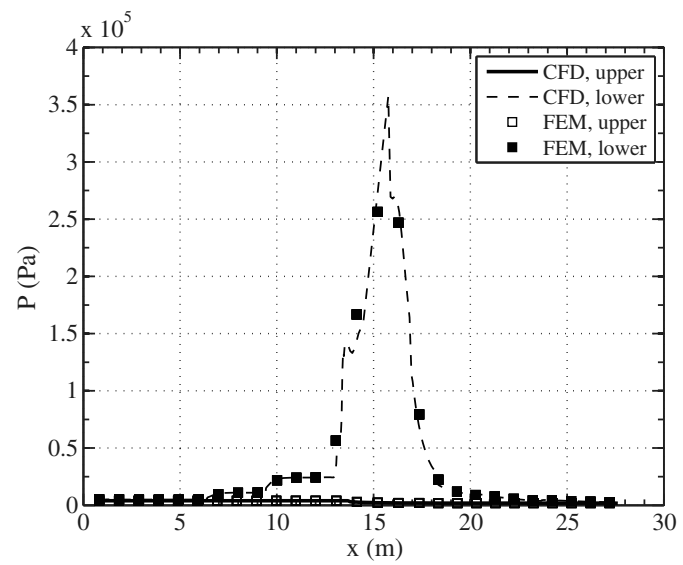

b) Pressure

Fig. 13 CHT and structural coupling; $\alpha_{f}=0 \mathrm{deg}, t=1 \mathrm{~h}$, and ER $=1.0$.

leading edges and trailing edges computed in the CHT model are applied as point forces and moments at the respective leading edge and trailing edge of the vehicle FEM. Therefore, the total loading is conserved from the CHT model to the FEM model.

\section{B. Aerothermoelastic Deflections}

The natural modes shape of the vehicle are shown in Fig. 14. The shaded areas represent contours of the magnitude of the deformation, $\|\boldsymbol{u}\|=\sqrt{u^{2}+v^{2}+w^{2}}$. The first two and fourth elastic modes correspond to the first longitudinal bending modes having a natural frequency of $12.3,19.2$, and $26.7 \mathrm{~Hz}$, respectively. The third mode at $25.9 \mathrm{~Hz}$ is a lateral bending mode. The fifth mode with natural frequency of $28.2 \mathrm{~Hz}$ is the first torsional mode.

The Young modulus of the titanium alloy varies linearly with temperature from 100 to $70 \%$ at 288 and $810 \mathrm{~K}$, respectively. The coefficient of thermal expansion varies from $7.74 \times 10^{-6}$ to $9.54 \times$ $10^{-6} \mathrm{~K}^{-1}$ at 288 and $810 \mathrm{~K}$, respectively. These values are representative of a high-temperature titanium alloy such as Ti-6Al-2Sn-4Zr$2 \mathrm{Mo}$ [54]. The initial temperature for the thermal expansion of the structure is set to $288 \mathrm{~K}$, which is the sea-level temperature in a standard atmosphere model.

The temperature contours on the lower surface of the FEM model of the vehicle are shown in Fig. 15 and correspond to the temperature shown in Fig. 13a. The highest temperature, $950 \mathrm{~K}$, is at the exit of the combustor. The lowest temperature on the upper surface is less than $600 \mathrm{~K}$

Similarly, pressure contours on the lower surface of the FEM are shown in Fig. 16 and correspond to the pressure shown in Fig. 13b. As expected, temperature and pressure are dependent only on the $x$ coordinate on the lower surface. The variation along the spanwise direction is due to the interpolation from the elements of the lateral skin comprising the sides of the vehicle.

The vehicle is in a straight and level flight at constant altitude and Mach number. The angle of attack is assumed to be $\alpha_{f}=0 \mathrm{deg}$. The temperature increases as a function of time. As the structure heats up, material degradation and thermal stresses decrease the natural frequencies, as shown in Fig. 17. The different bars in the figure correspond to different thermal loads. The variation in modal frequencies is of the order of $10 \%$ after an hour of flight at 0 deg angle of attack. For a uniform temperature of $800 \mathrm{~K}$, the variation in frequencies is of the order of $-16 \%$, which corresponds primarily to material degradation.

The static deformations are computed at different times. The aerothermoelastic deformation of the vehicle along its plane of symmetry $(y=0)$ is shown in Fig. 18. The leading edge and trailing edge of the body deflect upward due to the increasing temperature difference between the upper and lower surfaces at the inlet and nozzle, respectively. After one hour of flight, the amplitude of the

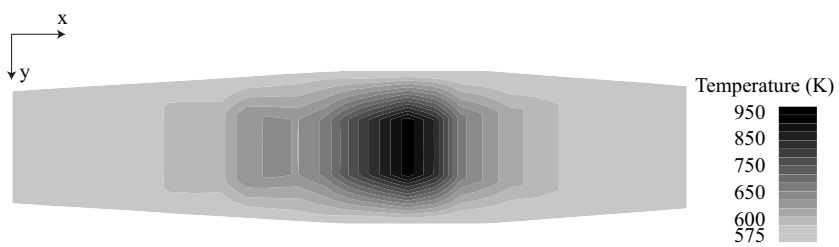

Fig. 15 Temperature contours at the lower surface of the vehicle at $\alpha_{f}=0 \mathrm{deg}, t=1 \mathrm{~h}$, and $\mathrm{ER}=1.0$.

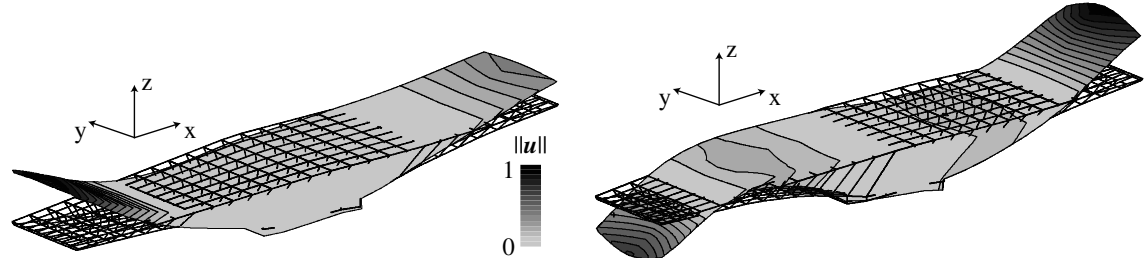

b) $f=19.2 \mathrm{~Hz}$

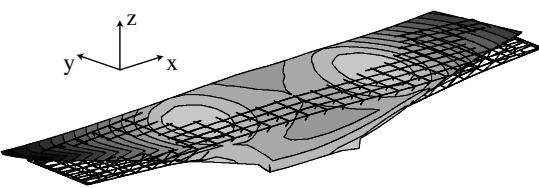

c) $f=25.9 \mathrm{~Hz}$
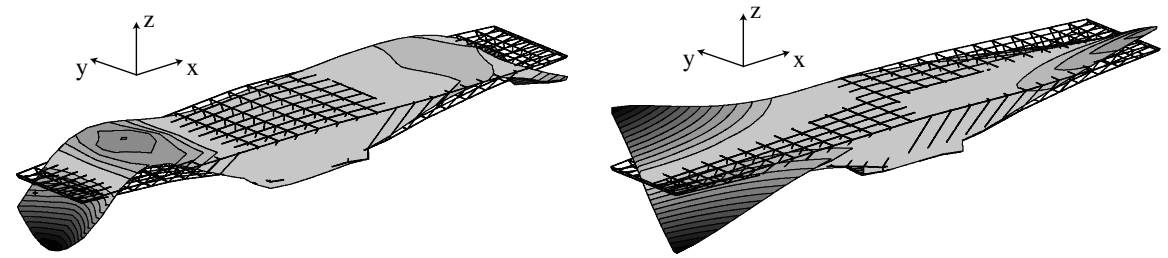

d) $f=26.7 \mathrm{~Hz}$

e) $f=28: 2 H z$

Fig. 14 First five normalized natural mode shapes. 


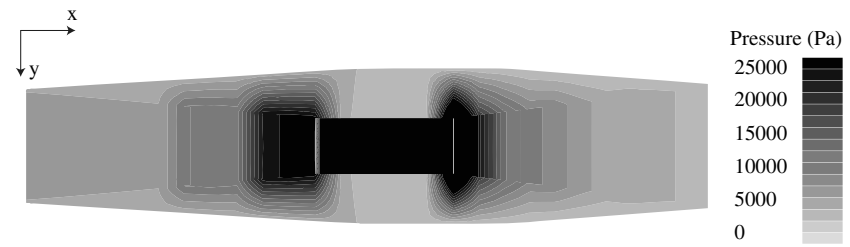

Fig. 16 Pressure contours at $\alpha_{f}=0 \mathrm{deg}, t=1 \mathrm{~h}$, and ER $=1.0$.

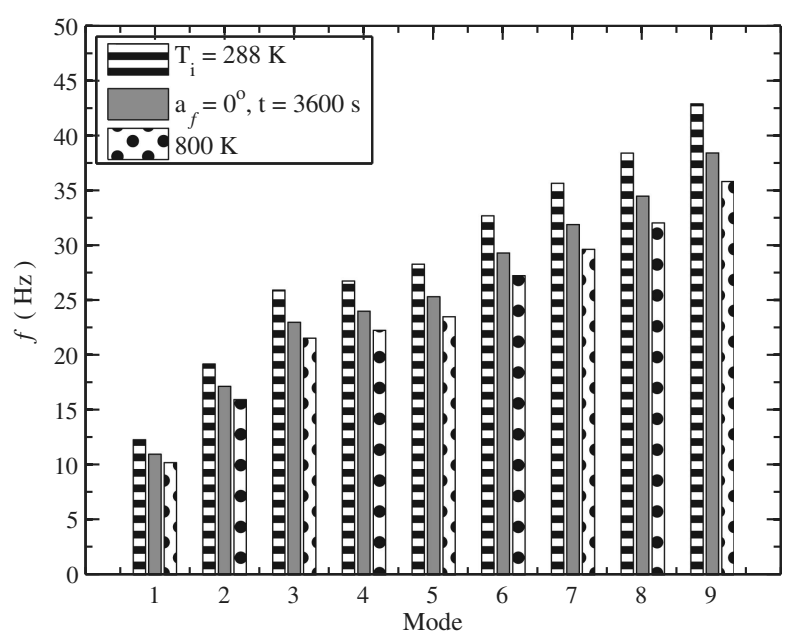

Fig. 17 Natural frequencies of the heated airframe. deflections is approximately $8 \mathrm{~cm}$, which corresponds to $0.6 \%$ of the length of the inlet from the leading of the vehicle to the leading edge of the cowl. The deflections vary significantly with time: the aeroelastic deformation may be limited initially, but as the vehicle flies and heats up, material degradation and thermal stresses play a significant role in deforming the vehicle. At the centerline, the cowl deflects downward due to high-pressure loading at its upper surface. It is important to note that the cowl is modeled using a single shell element through the thickness. For this reason, the temperature gradients that may occur between the upper and lower surfaces of the cowl are not accounted for. The temperature is assumed to be uniform across the thickness of the cowl. In an actual vehicle, similar to the inlet, the temperature at the upper surface of the cowl is higher than the temperature at the bottom of the cowl. However, some active cooling design may alleviate part of the temperature difference through the thickness. In the model, the cowl structure has been assumed to be sufficiently flexible to account for potential deformations as a result of high-pressure and thermal loading. Deflections of the order of 1.5 to $2 \mathrm{~cm}$ are obtained. The maximum deflection corresponds to approximately $0.9 \%$ of the width of the engine. At the edge of the engine, the cowl is attached to the vehicle, and its deformation follows the shape of the vehicle. The leading edge of the cowl deflects upward. The amplitude of the deflection is of the order of 0.4 times the deflection at the centerline at a 0 deg angle of attack. It dictates the range of the uncertain variable $\xi_{2}$ in the uncertainty propagation analysis.

In Fig. 19a, the vehicle deformations are computed for different angles of attack from -1 to $5 \mathrm{deg}$ at times $t=720$ and $t=3600 \mathrm{~s}$. The temperature distribution in the structure is due to the flight time

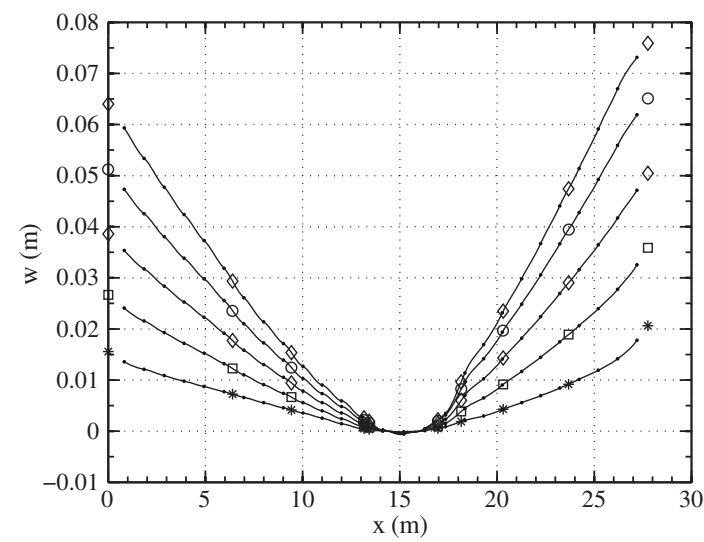

a) Body
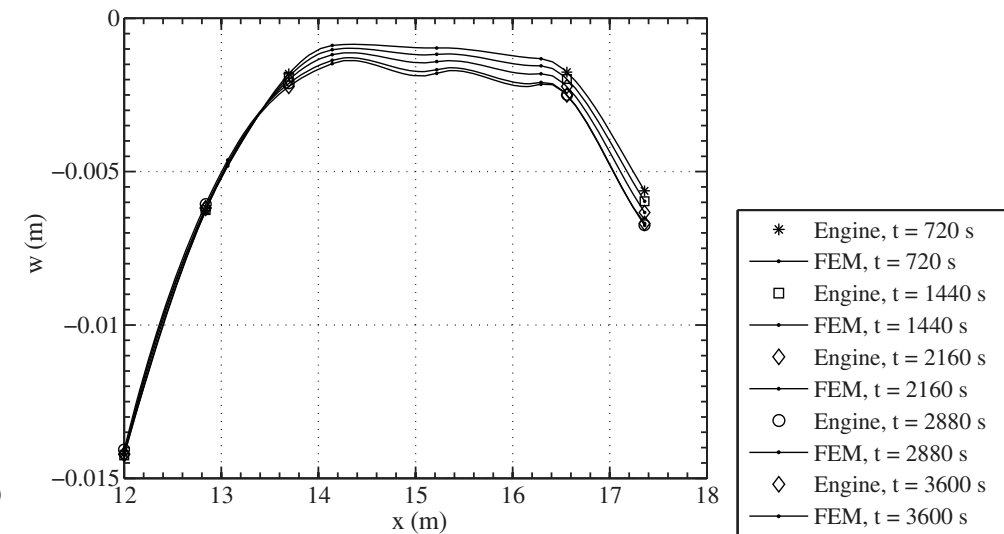

b) Cowl

Fig. 18 FEM deformation as a function of time along the centerline of the vehicle.

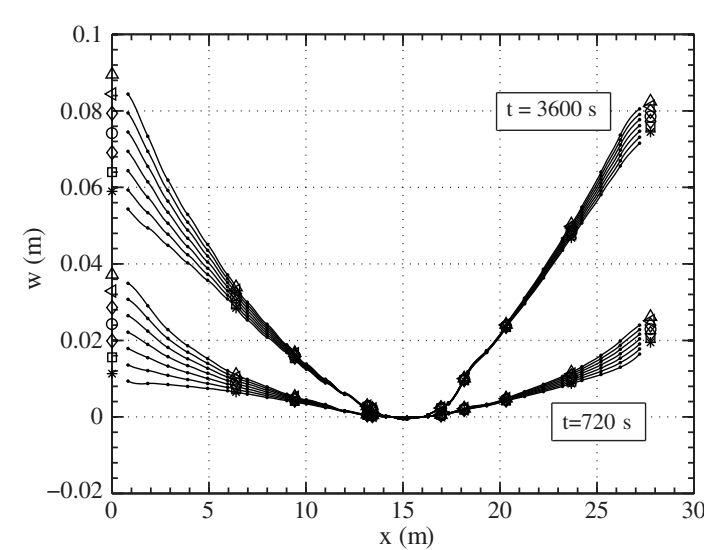

a) Vehicle
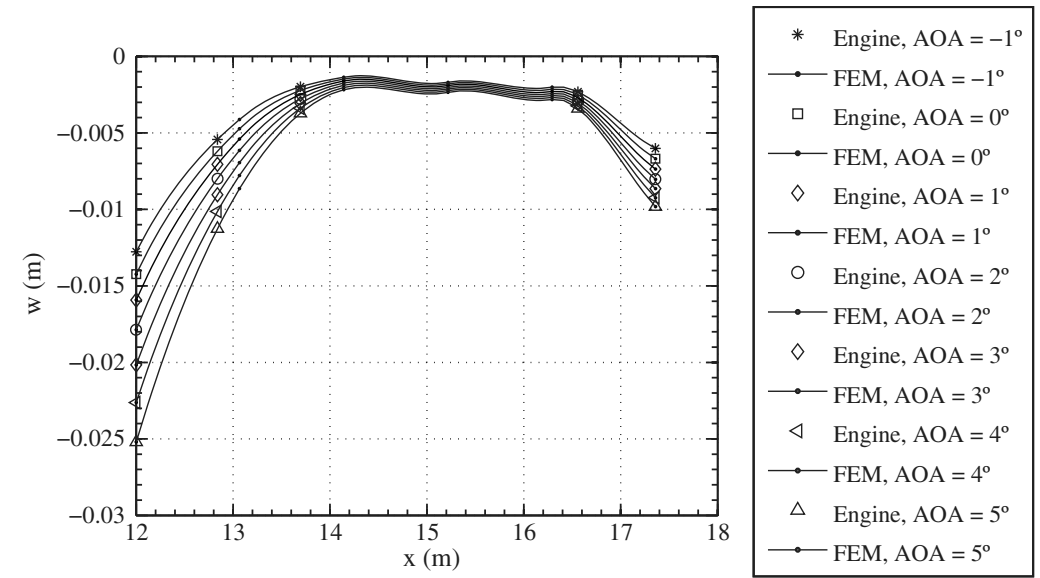

b) Cowl, $t=3600 \mathrm{~s}$

Fig. 19 FEM deformation as function of angle of attack (AOA); $\alpha_{f}=0 \mathrm{deg}$. 
Table 5 Displacements at the leading edges of the cowl and of the vehicle, $y=0$

\begin{tabular}{|c|c|c|c|}
\hline Deforma & tion & $u, \mathrm{~m}$ & $w, \mathrm{~m}$ \\
\hline \multicolumn{4}{|c|}{$t=720 \mathrm{~s}$} \\
\hline \multirow{4}{*}{$\begin{array}{l}\alpha_{f}=0 \mathrm{deg} \\
\alpha_{f}=1 \mathrm{deg}\end{array}$} & Vehicle & -0.0073 & 0.0156 \\
\hline & Cowl & -0.0039 & -0.0142 \\
\hline & Vehicle & -0.0073 & 0.0181 \\
\hline & Cowl & -0.0039 & -0.0142 \\
\hline \multicolumn{4}{|c|}{$t=3600 \mathrm{~s}$} \\
\hline \multirow[t]{2}{*}{$\alpha_{f}=0 \mathrm{deg}$} & Vehicle & 0.0114 & 0.0640 \\
\hline & Cowl & -0.0038 & -0.0142 \\
\hline \multirow[t]{2}{*}{$\alpha_{f}=1 \mathrm{deg}$} & Vehicle & 0.010 & 0.0803 \\
\hline & Cowl & -0.0044 & -0.0142 \\
\hline
\end{tabular}

Table 6 Displacement bounds and PDF for uncertainty propagation

\begin{tabular}{lcccc}
\hline \hline Deformation & Variable & Lower Bound & Upper bound & PDF \\
\hline Vehicle & $\xi_{1}$ & 0 & 1 & Uniform \\
Cowl & $\xi_{2}$ & -0.4 & 1 & Uniform \\
\hline \hline
\end{tabular}

elapsed, while the pressure loading corresponds to the attitude of the vehicle at a particular time. In Fig. 19a, deformations are due to a flight times of $t=720$ and $t=3600 \overline{\mathrm{s} \text { at }} \alpha_{f}=0 \mathrm{deg}$ angle of attack followed by a change of the angle of attack, which creates a different pressure loading on the heated vehicle. The results show that the variation of the deformation due to changes in angle of attack is about $40 \%$ of the maximum deformation and less than that due to the change in flight time. The deformation after one hour of flight is three times larger than that after 720 s. It implies that changes in temperature distribution have a greater effect on the deformation of the airframe than the changes in pressure loading. In Fig. 19b, results are shown for only $t=3600 \mathrm{~s}$, for the sake of clarity. The deformation of the cowl does not depend significantly of the flight history. Its deformation depends primarily on aerodynamic loading since the cowl is not subject to temperature gradients across its thickness in this model.

In Table $\underline{5}$, the displacements at two different flight times and two different angles of attack are given. The axial deformations of the cowl leading edge are relatively small. The difference between the vertical displacements between the two trajectories is $16 \%$ at $t=720 \mathrm{~s}$ and $25 \%$ at $t=3600 \mathrm{~s}$. The flight time increases the deformation of the vehicle.

Once the aerothermoelastic deflections have been studied, the uncertainty propagation analysis is performed for the two uncertain variables corresponding to the amplitude of the deformations.

\section{Uncertainty Propagation Results}

The uncertainties associated with thermal deflections of the vehicle and cowl are propagated through the analysis, and their impact on the axial force $F_{x}$ is quantified. The 2D MASIV code predicts a force per unit length, which is multiplied by the width of the cowl, $2.1 \mathrm{~m}$, to give a force $F_{x}$ in $N$. In Table 6 , the amplitude $\xi_{1}$ of the deformation of the vehicle is assumed to vary between 0 and 1 , and it corresponds to the deformation observed during the first hour of the flight. The amplitude of the deformation of the cowl $\xi_{2}$ varies between -0.4 and 1 to represent the range of variation encountered during the first hour of flight and encompass the deformation shape that varies significantly from the centerline to the sides of the cowl.

A convergence study is performed to determine the degree of the polynomial for the response surface that produces an accurate approximate of the analysis. A fifth-order polynomial response surface is constructed based on $(5+1)^{2}=36$ analysis runs; i.e., six collocation points for the two random variables. Using this
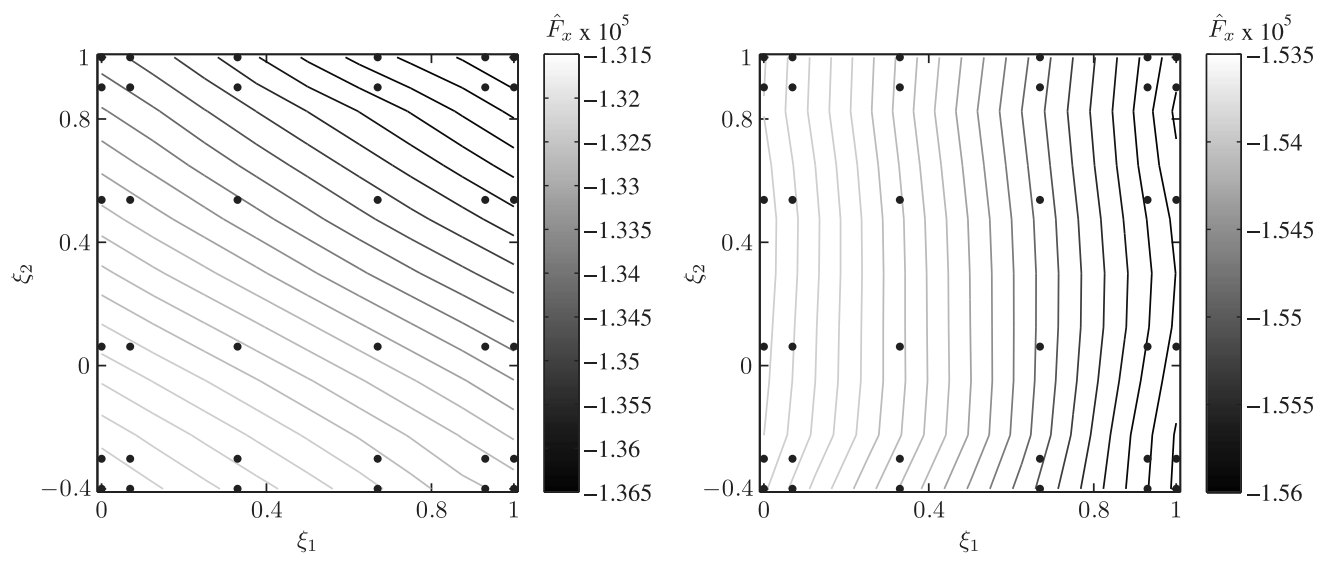

a) Mach 8, $\alpha=-1^{\circ}$

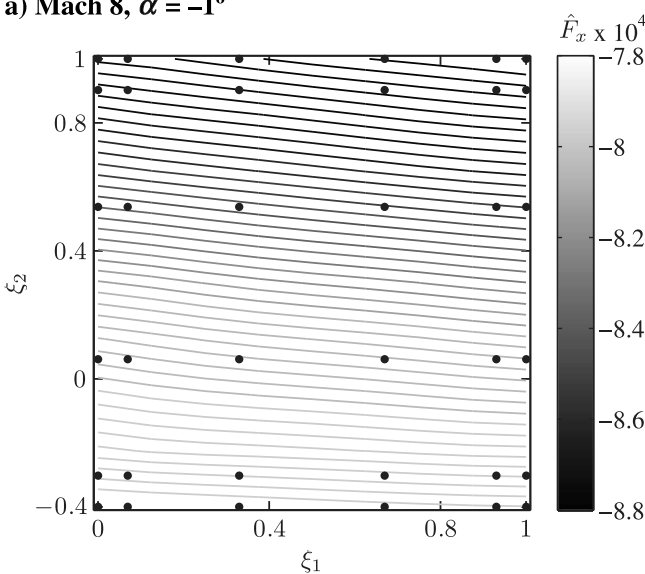

c) Mach $8, \alpha=5^{\circ}$

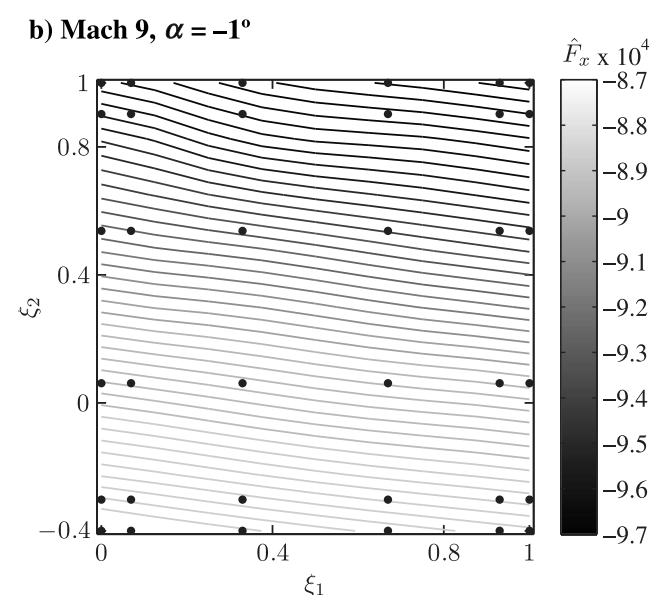

c) Mach 9, $\alpha=5^{\circ}$

Fig. 20 Response surfaces and collocation points for $\alpha_{f}=0 \mathrm{deg}$ and $\mathrm{ER}=0.5$. 
information, 50,000 IMCSs are performed on the polynomial response surface generated by the ESC. The ESC approach is chosen to prevent extrapolation and thus captures the boundaries of the uncertain parameters in the design space accurately, which is important since the minimum and maximum values of $F_{X}$ are located at the boundary of the uncertain design space. The accuracy of the polynomial response surface is evaluated by comparing its prediction with the complete analysis at 77 uniformly distributed reference points that are different from the collocation points. For this case, the maximum error is less than $0.8 \%$ of the deterministic value for all equivalence ratios and angles of attack for the 81 test points. Therefore, the polynomial response surface is considered to be a good approximation of the MASIV analysis. The mean and standard deviation predicted by the IMCS and numerical quadrature are within $0.7 \%$. The response surfaces are shown in Figs. 20a-20d. The relation between both uncertain variables and the force $\overline{F_{x}}$ is strongly

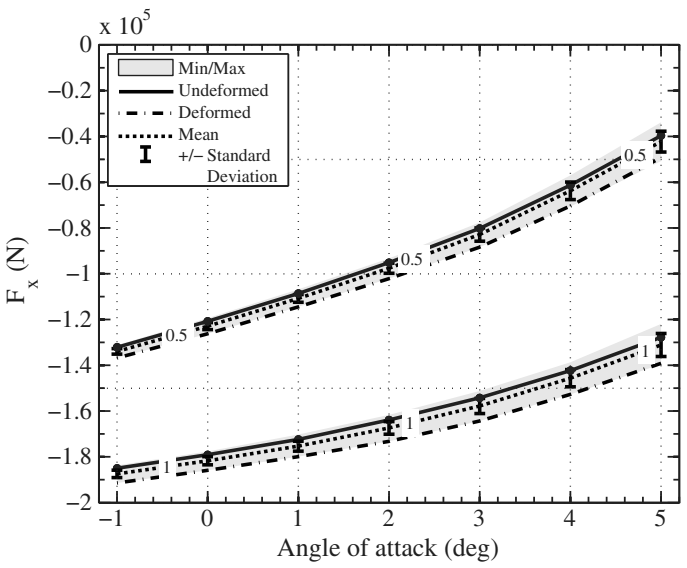

a) Mach 8

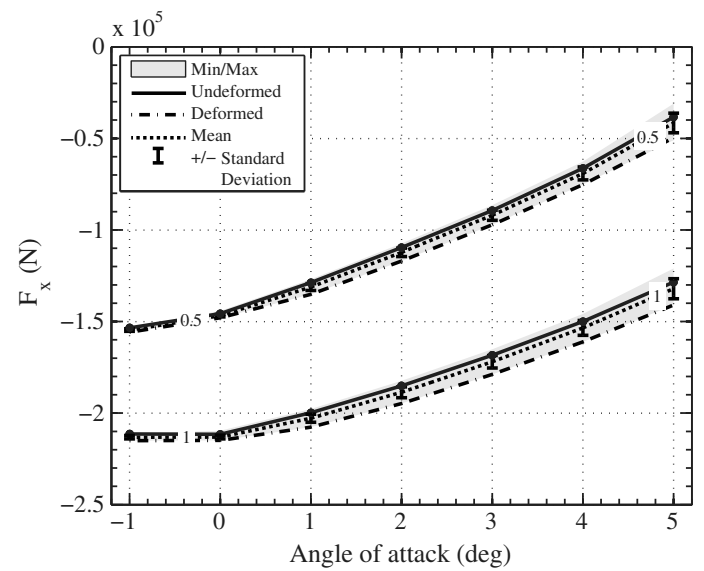

a) Mach 9

Fig. 21 Uncertainty propagation results for $\alpha_{f}=0 \mathrm{deg}$.

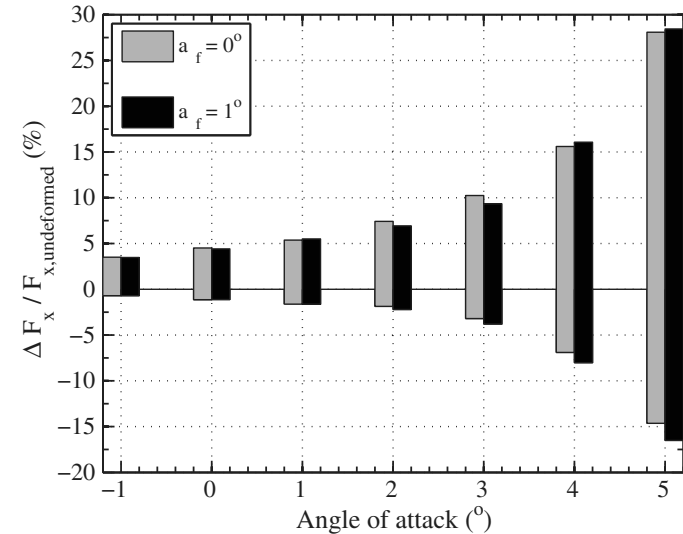

a) $\mathrm{ER}=0.5$

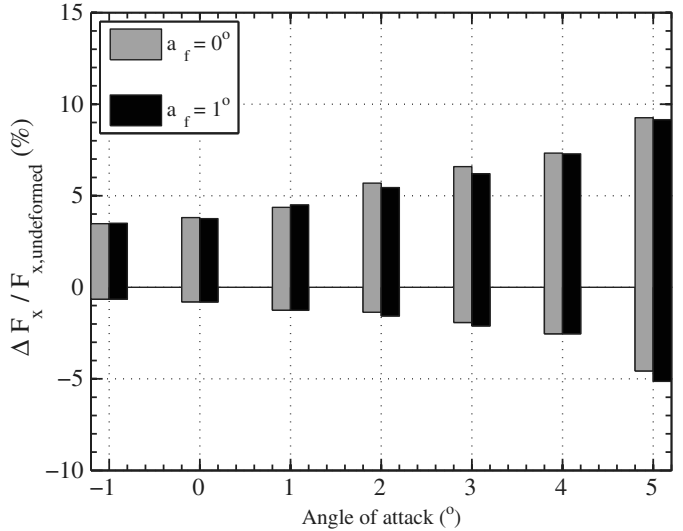

b) $\mathrm{ER}=1.0$

Fig. 22 Comparison of uncertainty propagation results for two different trajectories, $M_{\infty}=8$.

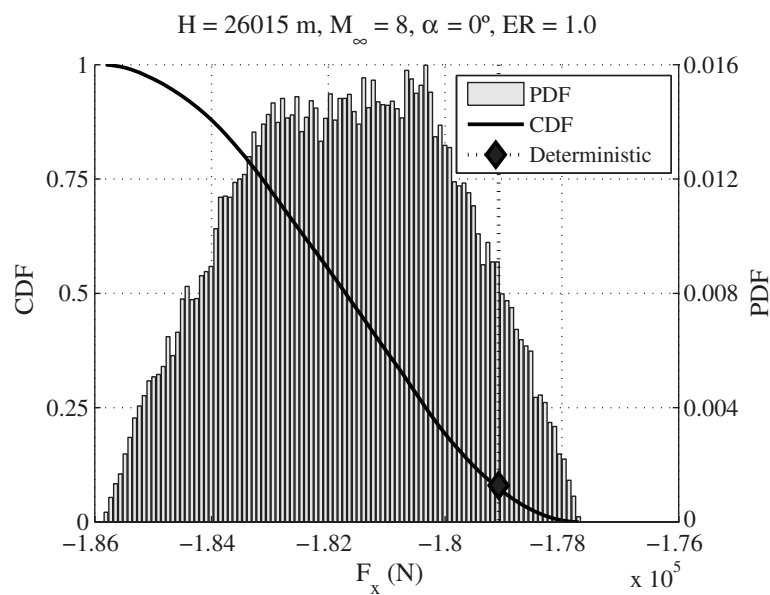

a) $F_{x}, \alpha=0$

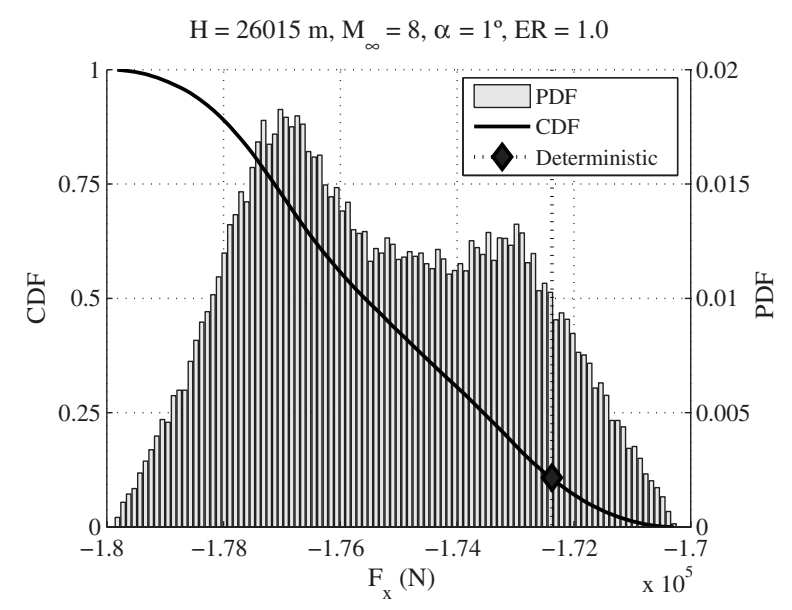

b) $F_{x}, \alpha=1$

Fig. 23 Uncertainty propagation results for Mach 8, $\alpha_{f}=0 \mathrm{deg}, t=1 \mathrm{~h}$, and ER $=1$. 
dependent on the angle of attack and Mach number. At a low angle of attack, $\xi_{1}$ and $\xi_{2}$ affect significantly the engine performance. At higher angles of attack, $\xi_{2}$ prevails; i.e., the deformation of the cowl prevails.

The results of the uncertainty propagation study are shown in Fig. 21a. The full line corresponds to the predicted axial force as a function of the angle attack for two different equivalence ratios, $\mathrm{ER}=0.5$ and $\mathrm{ER}=1.0$. From the deformed configuration, represented by the dashed line $\left(\xi_{1}=1\right.$ and $\left.\xi_{2}=1\right)$, it is evident that the performance of the engine is affected by the deformation.

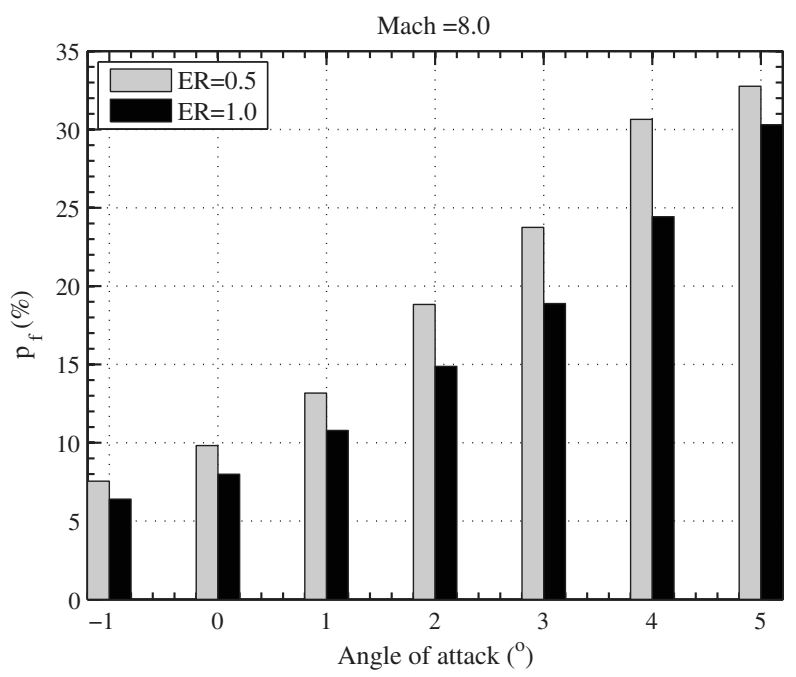

Fig. 24 Probability of failure.

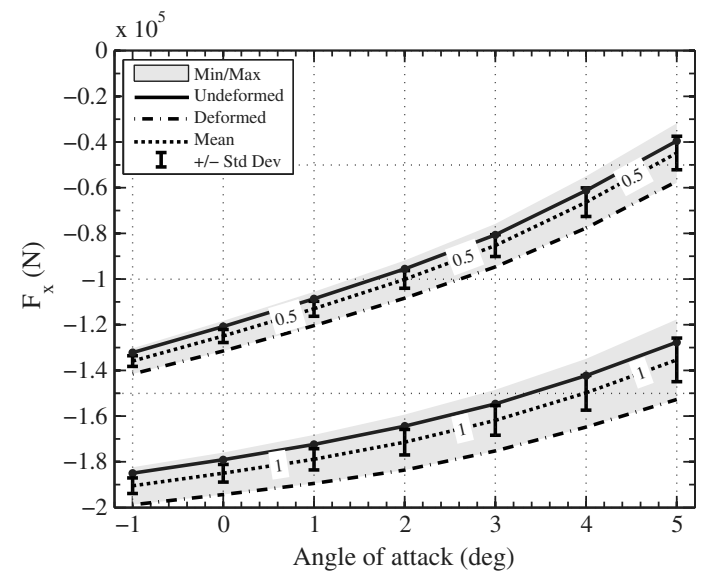

a) $F_{x}$, mach 8

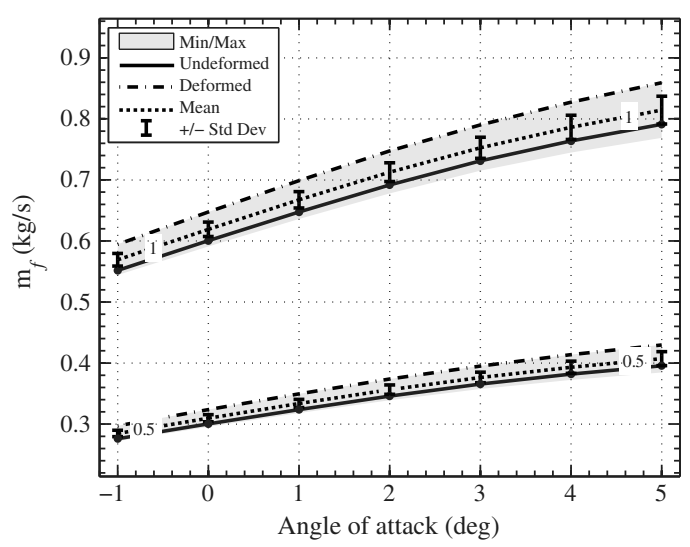

c) Mach 8, fuel flow mass rate, $\boldsymbol{m}_{f}$
Vehicle deformation upward and cowl deformation downward increase the magnitude of the axial force. This is because of the additional compression that occurs in the deformed inlet as well as an increased mass flow rate in the engine. In Fig. 21a, the gray areas represent the full range of the axial force given the uncertainty in the deformation of the geometry. The change of performance is relatively small in magnitude and varies with the angle of attack from 4 to $28 \%$ of the value predicted for the undeformed configuration at $E R=0.5$. The mean values are indicated by the dotted line. Error bars indicate the value of the mean plus or minus the standard deviation. The same deformation shapes obtained for Mach 8 are also used to perform the analysis of the engine performance at a Mach number of 9 . The change in Mach number is used as an indicator of whether the same level of deformations has a different effect on engine performance at a different flight condition. The results shown in Fig. $21 \mathrm{~b}$ indicate that this magnitude of deformations has a similar effect on engine performance at Mach 9. This information is a simple sensitivity study, which could be useful during vehicle design when estimating the level of acceptable deformation.

In Fig. 22, the results of the uncertainty propagation are normalized with respect to the value for the undeformed configuration and compared for two different trajectories. The first trajectory corresponds to a flight for one hour at $\alpha_{f}=0 \mathrm{deg}$ angle of attack at Mach 8 and an altitude of $26 \mathrm{~km}$. The second one corresponds to a similar flight condition with an angle of attack of $\alpha_{f}=1 \mathrm{deg}$. The vertical deformation at the leading edge of the vehicle is $25 \%$ higher for the second case because of the additional increase of temperature due to the variation in the flight condition. The cowl deformations are almost equal in both cases. Propulsion performance is affected in a similar manner in both cases.

The output probability distribution extracted from IMCS results are shown in Fig. 23. There is a significant probability that the

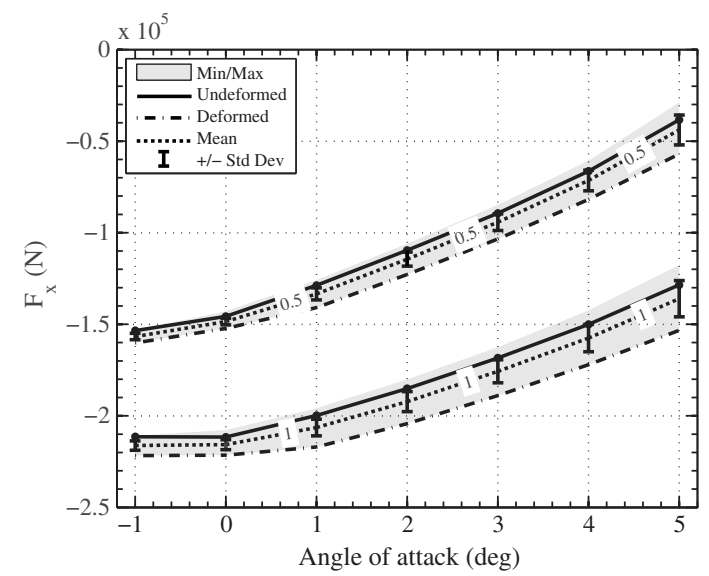

b) $F_{x}$, mach 9

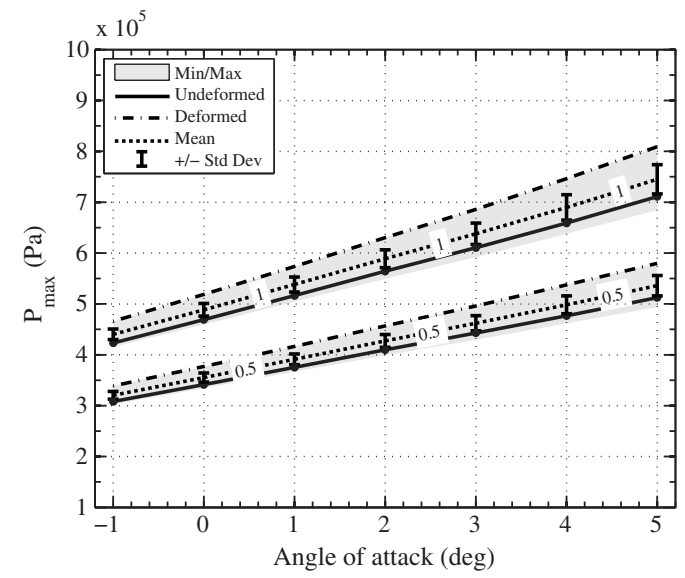

d) Mach 8, maximum pressure in the combustor

Fig. 25 Uncertainty propagation results for $\alpha_{f}=1 \mathrm{deg}$ and constant ER. 
magnitude of the axial force increases due to the deformation. In each figure, the horizontal axis shows the range of the axial force. The PDF of the output, as represented by the bars, indicates the regions with higher probability. The cumulative density function (CDF), depicted with the curve, gives the probability that the output is smaller than the given value of the output $f(\xi)$ : for instance, the probability that $\left\|F_{x}\right\|$ is less than the deterministic value is indicated by the symbols in each figure.

The probability of failure $p_{f}$ is defined as the probability that the magnitude of the axial force is less than its deterministic value. Its value is calculated based on the IMCS results and the CDF. It varies from a few percent to $34 \%$ at a 5 deg angle of attack as illustrated in Fig. 24. These results clearly demonstrate the additional information that is obtained by incorporating uncertainty in propulsion analysis problems.

To show the effect of keeping a constant equivalence ratio in the undeformed configuration, a similar study is performed without prescribing a constant fuel flow mass rate. Results shown in Figs. 25a and $25 \mathrm{~b}$ indicate that there is a significant increase in the effect of deformation on the change in axial force for both Mach 8 and 9. The range increases to up to $50 \%$ at an angle of attack of $\alpha=5 \mathrm{deg}$ and $\mathrm{ER}=0.5$. In addition, more fuel is injected in the combustor as illustrated in Fig. 25c. Thus, the range of the vehicle may decrease. The increased release of energy in the combustor affects the maximum pressure as depicted in Fig. 25d. The deformation increases the maximum pressure in the combustor that may significantly affect the chemistry of the combustion process. It is important to note that the reaction rates are interpolated from a database based on the local temperature. Currently, the database is limited, and its extension to a wider range of temperatures is planned for the future.

\section{Conclusions}

The results indicate that aerothermal deformations can be a source of uncertainty in air-breathing propulsion system modeling for hypersonic vehicles. Reduced-order models used in hypersonic aeroelastic and aerothermoelastic analyses based on insufficient knowledge associated with this class of problems require an uncertainty quantification approach:

1) The complexity of high-fidelity aerothermoelastic analyses requires expensive computations that are not suitable for analyzing integrated airframe-propulsion effects. However, estimating aerothermoelastic deflections at an early stage and propagating them through the propulsion analysis can alleviate the computational cost of the fully coupled analysis. Thus, it provides a first step toward an improved understanding for the effect of flexibility and thermal deformations on an airframe-integrated scramjet engine system.

2) While the deformation due to the aerothermoelastic effects is relatively small deformation, this sheds useful light on the understanding and quantification of the performance of the airframeintegrated engine for air-breathing hypersonic vehicles.

3) The cowl is identified as an important contributor to the uncertainty and sensitivity of the integrated propulsion system analysis. Accurate modeling of the thermal gradient through the main components of the structure is required. The structural model has to account for thermal gradients through the thickness of the vehicle airframe and cowl.

4) Accurate modeling of the aerodynamic heating, flight history, and control laws are required to fully understand the consequences of aerothermoelastic deformation on the overall performance of the vehicle throughout its mission.

\section{Acknowledgments}

This research is funded under NASA grant NNX08AB32A with Donald Soloway and Jorge Bardina as technical monitors. Support was also provided by AFRL grant FA 8650-07-2-3744 for Michigan AFRL Collaborative Center for Control Science, monitored by David Doman and Michael Bolender.

\section{References}

-11] McNamara, J. J., Friedmann, P. P., Powell, K., Thuruthimattam, B., and Bartels, R., "Aeroelastic and Aerothermoelastic Behavior in Hypersonic Flow," AIAA Journal, Vol. 46, No. 10, 2008, pp. 2591-2610. doi:10.2514/1.36711

[2] Fidan, B., Mirmirani, M., and Ioannou, P. A., "Flight Dynamics and Control of Air-Breathing Hypersonic Vehicles: Review and New Directions," Proceedings of the 12th AIAA International Space Planes and Hypersonic Systems and Technologies, AIAA Paper 2003-7081, Dec. 2003.

[3] Hallion, R. P., "The History of Hypersonics, or Back to the Future: Again and Again," Proceedings of the 43rdAerospace Sciences Meeting and Exhibit, AIAA Paper 2005-0329, Jan. 2005.

-[4] Dolvin, D. J., "Hypersonic International Flight Research and Experimentation (HIFiRE), Fundamental Sciences and Technology Development Strategy," Proceedings of the 15th AIAA International Space Planes and Hypersonic System and Technologies Conference, AIAA Paper 2008-2581, April-May 2008.

-[5] Voland, R. T., Huebner, L. D., and McClinton, C. R., "X-43A Hypersonic Vehicle Technology Development," Acta Astronautica, Vol. 59, Nos. 1-5, 2006, pp. 181-191. doi:10.1016/j.actaastro.2006.02.021

-[6] Bertin, J. J., and Cummings, R. M., "Fifty Years of Hypersonics: Where We've Been, Where We're Going," Progress in Aerospace Sciences, Vol. 39, Nos. 6-7, 2003, pp. 511-536. doi:10.1016/S0376-0421(03)00079-4

-[7] Rodriguez, A. A., Dickeson, J. J., Cifdaloz, O., Kelkar, A., Vogel, J. M., and Soloway, D., "Modeling and Control of Scramjet-Powered Hypersonic Vehicles: Challenges, Trends, and Tradeoffs," Proceedings of AIAA Guidance, Navigation and Control Conference and Exhibit, AIAA Paper 2008-6793, Aug. 2008.

- [8] Fry, R., "A Century of Ramjet Propulsion Technology Evolution," Journal of Propulsion and Power, Vol. 20, No. 1, 2004, pp. 27-58. doi: $10.2514 / 1.9178$

- [9] Tang, M., and Chase, R. L., "The Quest for Hypersonic Flight with Air-Breathing Propulsion," 15th International Space Planes and Hypersonic Systems and Technologies Conference, AIAA Paper 20082546, April-May 2008.

[10] Heiser, W. H., and Pratt, D. T., Hypersonic Airbreathing Propulsion, AIAA, Washington, D.C., 1994, pp. 55-123.

[11] Smart, M. K., "Experimental Testing of a Hypersonic Inlet with Rectangular-to-Elliptical Shape Transition," Journal of Propulsion and Power, Vol. 17, No. 2, 2001, pp. 276-283. doi: $10.2514 / 2.5774$

[12] Schulte, D., Henckels, A., and Neubacher, R., "Manipulation of Shock Boundary-Layer Interactions in Hypersonic Inlets," Journal of Propulsion and Power, Vol. 17, No. 3, 2001, pp. 585-590. doi: $10.2514 / 2.5781$

[13] Dalle, D., Torrez, S. M., and Driscoll, J. F., "Rapid Analysis of Scramjet and Linear Plug Nozzles," Journal of Propulsion and Power, Vol. 28, No. 3, May 2012, pp. 545-555. doi:10.2514/1.B34391

[14] Dalle, D. J., Frendreis, S., Driscoll, J. F., and Cesnik, C. E. S. "Hypersonic Vehicle Flight Dynamics with Coupled Aerodynamic and Reduced-Order Propulsive Models," Proceedings of the AIAA Atmospheric Flight Mechanics Conference, AIAA Paper 2010-7930, Aug. 2010.

[15] Torrez, S. M., Dalle, D. J., and Driscoll, J. F., "New Method for Computing Performance of Choked Reacting Flows and Ram-to-Scram Transition," Journal of Propulsion and Power, Vol. 29, No. 2, 2013, pp. 433-445.

doi:10.2514/1.B34496

- [16] Raney, D. L., McMinn, J. D., and Pototzky, A. S., "Impact of Aeroelastic-Propulsive Interactions on Flight Dynamics of a Hypersonic Vehicle," Journal of Aircraft, Vol. 32, No. 2, 1995, pp. 355-362. doi:10.2514/3.46723

[17] Bolender, M. A., and Doman, D. D., "Modeling Unsteady Heating Effects on the Structural Dynamics of a Hypersonic Vehicle," Proceedings of the AIAA Atmospheric Flight Mechanics Conference and Exhibit, AIAA Paper 2006-6646, Aug. 2006.

[18] Anderson, J. D., Hypersonic and High Temperature Gas Dynamics, McGraw-Hill Editions, McGraw-Hill, New York, 1989.

[19] Bertin, J. J., Hypersonic Aerothermodynamics, AIAA Education Series, AIAA, Washington, D.C., 1994, pp. 335-439.

[20] Dugundji, J., and Calligeros, J. M., "Similarity Laws for Aerothermoelastic Testing," Journal of Aerospace Sciences, Vol. 29, No. 8 , Aug. 1962, pp. 935-950.

doi: $10.2514 / 8.9663$ 
[21] Schütte, G., and Staudacher, S., "Probabilistic Aspects of Scramjet Design," Journal of Propulsion and Power, Vol. 25, No. 2, 2009, pp. 281-288. doi:10.2514/1.38195

[22] Chavez, F. R., and Schmidt, D. K., "Flight Dynamics and Control of Elastic Hypersonic Vehicles-Modeling Uncertainties," Proceedings of AIAA Guidance, Navigation and Control Conference, AIAA Paper 1994-3629, Aug. 1994.

[23] Witteveen, J. A., Duraisamy, K., and Iaccarino, G., "Uncertainty Quantification and Error Estimation in Scramjet Simulation," 17th AIAA International Space Planes and Hypersonic Systems and Technologies Conference, AIAA Paper 2011-2283, April 2011.

[24] Wang, Q., Duraisamy, K., Alonso, J. J., and Iaccarino, G., "Risk Assessment of Scramjet Unstart Using Adjoint-Based Sampling Methods," AIAA Journal, Vol. 50, No. 3, 2012, pp. 581-592. doi:10.2514/1.J051264

- [25] Eldred, M. S., and Burkardt, J., "Comparison of Non-Intrusive Polynomials Chaos and Stochastic Collocation Methods for Uncertainty Quantification," Proceedings of the 47th AIAA Aerospace Sciences Meeting Including the New Horizons Forum and Aerospace Exposition, AIAA Paper 2009-0976, Jan. 2009.

[26] Lamorte, N., Friedmann, P. P., Glaz, B., Culler, A. J., Crowell, A. R., and McNamara, J. J., "Uncertainty Propagation in Hypersonic Aerothermoelastic Analysis," Journal of Aircraft, Vol. 51, No. 1, 2014, pp. 192-203. doi:10.2514/1.C032233

[27] Dalle, D., Fotia, M., and Driscoll, J., "Reduced-Order Modeling of TwoDimensional Supersonic Flows with Applications to Scramjet Inlets," Journal of Propulsion and Power, Vol. 26, No. 3, 2010, pp. 545-555. doi:10.2514/1.46521

[28] Torrez, S. M., Driscoll, J. F., Dalle, D. J., and Fotia, M. L., "Preliminary Design Methodology for Hypersonic Engine Flowpaths," Proceedings of the 16th AIAA/DLR/DGLR International Space Planes and Hypersonic Systems and Technologies Conference, AIAA Paper 20097289 , Oct. 2009.

[29] Torrez, S. M., Driscoll, J. F., Dalle, D. J., and Micka, D. J., "Scramjet Engine Model MASIV: Role of Mixing, Chemistry and Wave Interaction," Proceedings of the 45th AIAA/ASME/SAE/ASEE Joint Propulsion Conference and Exhibit, AIAA Paper 2009-4939, Aug. 2009.

[30] Bisplinghoff, R. L., "Some Structural and Aeroelastic Considerations of High-Speed Flight," Journal of Aeronautical Sciences, Vol. 23, No. 4, April 1956, pp. 289-321. doi: $10.2514 / 8.3557$

[31] Hunt, J. L., and Eiswirth, E. A., "NASA's Dual-Fuel Airbreathing Hypersonic Vehicle Study," Proceedings of the 7th International Space Planes and Hypersonics Systems and Techonology Conference, AIAA Paper 1996-4591, Nov. 1996.

[32] Weirich, T. L., Fogarty, W., Dry, K., Iqbal, A., and Moses, P. L., "DualFuel Vehicle Airframe and Engine Structural Integration," Proceedings of the 7th International Space Planes and Hypersonic Systems and Technologies Conference, AIAA Paper 1996-4594, 1996. doi:10.2514/6.1996-4594

[33] Hunt, J. L., Laruelle, G., and Wagner, A., "Systems Challenges for Hypersonic Vehicles," Proceedings of the Future Aerospace Technology in the Service of the Alliance, AGARD Conference, Vol. 3, AGARD, Palaiseau, France, April 1997.

[34] Bolender, M. A., and Doman, D. D., "Nonlinear Longitudinal Dynamical Model of an Air-Breathing Hypersonic Vehicle," Journal of Spacecraft and Rockets, Vol. 44, No. 2, 2007, pp. 374-387. doi: $10.2514 / 1.23370$

[35] Ko, W., and Gong, L., Thermostructural Analysis of Unconventional Wing Structures of a Hyper-X Hypersonic Flight Research Vehicle for the Mach 7 Mission, NASA Dryden Flight Research Center, TP-2001210398, 2001.

[36] Shih, P., Prunty, J., and Mueller, R., "Thermostructural Concepts for Hypervelocity Vehicles," Journal of Aircraft, Vol. 28, No. 5, 1991, pp. 337-345.

doi: $10.2514 / 3.46032$

[37] Tenney, D. R., Lisagor, W. B., and Dixon, S. C., "Materials and Structures for Hypersonic Vehicles," Journal of Aircraft, Vol. 26, No. 11, 1989, pp. 953-970. doi: $10.2514 / 3.45868$

[38] Orton, G. F., Scuder, L. F., and Artus, J., "Airbreathing Hypersonic Aircraft and Transatmospheric Vehicles," Future Aeronautical and Space Systems, Vol. 172, 1997, pp. 297-371.

[39] Ko, W. L., and Jackson, R. H., "Combined Compressive and Shear Buckling Analysis of Hypersonic Aircraft Structural Sandwich Panels," National Aeronautics and Space Administration Tech. Rept. NASATM-4290, Edwards AFB Dryden Flight Research Center, May 1991.

[40] CFD++ User Manual, Turbulence Modelling, Ver. 10.1, Metacomp Technologies, Inc., Agoura Hills, CA, 2010.

[41] Culler, A., and McNamara, J. J., "Studies on Fluid-Thermal-Structural Coupling for Aerothermoelasticity in Hypersonic Flow," AIAA Journal, Vol. 48, No. 8, 2010, p. 1721. doi:10.2514/1.J050193

[42] Myers, D. E., Martin, C. J., and Blosser, M. L., "Parametric Weight Comparison of Current and Proposed Thermal Protection System (TPS) Concepts," Proceedings of the 33rd Thermophysics Conference, AIAA Paper 1999-3459, June-July 1999.

[43] Myers, D. E., Martin, C. J., and Blosser, M. L., "Parametric Weight Comparison of Advanced Metallic, Ceramic Tile, and Ceramic Blanket Thermal Protection Systems," NASA TM-2000-210289, June 2000.

[44] Murugan, S., Harursampath, D., and Ganguli, R., "Material Uncertainty Propagation in Helicopter Nonlinear Aeroelastic Response and Vibration Analysis," AIAA Journal, Vol. 46, No. 9, 2008, pp. 2332 2344. doi: $10.2514 / 1.35941$

[45] Pettit, C., "Uncertainty Quantification in Aeroelasticity: Recent Results and Research Challenges," Journal of Aircraft, Vol. 41, No. 5, Sept.Oct. 2008, pp. 1217-1229. doi: $10.2514 / 1.3961$

[46] Hosder, S., Walters, R. W., and Balch, M., "Efficient Uncertainty Quantification Applied to the Aeroelastic Analysis of a Transonic Wing," Proceedings of the 46th AIAA Aerospace Sciences Meeting and Exhibit, AIAA Paper 2008-0729, Jan. 2008.

[47] Golub, G. H., and Welsch, J. H., "Calculation of Gauss Quadrature Rules," Mathematics of Computation, Vol. 23, No. 106, April 1969, pp. 221-230. doi:10.1090/S0025-5718-69-99647-1

[48] Klimke, A., Sparse Grid Interpolation Toolbox User's Guide, Ver. 5.1, Inst. für Angewandte Analysis und Numerische Simulation, Univ. of Stuttgart, Stuttgart, Germany, 2008, pp. 11-52.

[49] Bunjgartz, H.-J., and Dirnstorfer, S., "Multivariate Quadrature on Sparse Grids," Computing, Archives for Scientific Computing, Vol. 71 , No. 1, Aug. 2003, pp. 84-114.

[50] Sacks, J., Welch, W. J., Mitchell, T. J., and Wynn, H. P., "Design and Analysis of Computer Experiments," Statistical Science, Vol. 4, No. 4, 1989, pp. 409-435.

[51] Jekabsons, G., Adaptive Regression Splines Toolbox for MATLAB®, Ver. 1.3 (reference manual), Inst. of Applied Computer Systems, Riga Technical Univ., Dec. 2009, pp. 3-17.

[52] Friedman, J. H., "Multivariate Adaptive Regression Splines," Annals of Statistics, Vol. 19, No. 1, March 1991, pp. 1-67.

[53] Bolender, M., and Doman, D., "Modeling Unsteady Heating Effects on the Structural Dynamics of a Hypersonic Vehicle," Proceedings of AIAA Atmospheric Flight Mechanics Conference and Exhibit, AIAA Paper 2006-6646, Aug. 2006.

[54] "5H-Metallic Materials and Elements for Aerospace Vehicle Structures," Department of Defense Handbook, Vol. 31, U.S. Dept. of Defense, Handbook MIL-HDBK, 2003.
R. Bowersox Associate Editor 
This article has been cited by:

1. Chukwuka C. Mbagwu, James F. Driscoll, Derek J. Dalle, Sean M. Torrez. Combustion Efficiencies and Flameout Limits Computed for a Hypersonic Vehicle During Ascent. Journal of Propulsion and Power, ahead of print1-12. [Abstract] [Full Text] [PDF] [PDF Plus]

2. Qing Chen, Baoqiang Zhang, Jing Yang, Guoqiang Su. Model Updating and Uncertainty Propagation in Aerothermoelastic Analysis for $\mathrm{C} / \mathrm{SiC}$ Panel of Ceramic Matrix Composite . [Citation] [PDF] [PDF Plus]

3. Anton Vanderwyst, Vinod Sharma, Christopher Martin. Big Data Algorithms and Workflow Needed to Assess Highly Maneuverable, Flexible Vehicles . [Citation] [PDF] [PDF Plus]

4. Christopher D. Marley, James F. Driscoll. Modeling an Active and Passive Thermal Protection System for a Hypersonic Vehicle . [Citation] [PDF] [PDF Plus]

5. Anton Vanderwyst, Andrew Shelton, Christopher L. Martin. A Computationally Efficient, Multi-fidelity Assessment of Jet Interactions for Highly Maneuverable Missiles . [Citation] [PDF] [PDF Plus] 